NBER WORKING PAPER SERIES

\title{
INFORMATION, SCHOOL CHOICE, AND ACADEMIC ACHIEVEMENT: EVIDENCE FROM TWO EXPERIMENTS
}

\author{
Justine S. Hastings \\ Jeffrey M. Weinstein \\ Working Paper 13623 \\ http://www.nber.org/papers/w13623
NATIONAL BUREAU OF ECONOMIC RESEARCH
1050 Massachusetts Avenue
Cambridge, MA 02138 \\ November 2007
}

We would like to thank the Charlotte-Mecklenburg Public School District for allowing us to study public school choice in the district. Jason Ghassemi, Jacob Gramlich, and Hillary Gramlich provided excellent assistance creating and distributing the information sheets. We would also like to thank Joseph Altonji, Judy Chevalier, Stefano Della Vigna, Alan Gerber, Edward Glaeser, Donald Green, Caroline Hoxby, Dean Karlan, Lawrence Katz, Jeffrey Kling, Michael Kremer, Sendhil Mullainathan, Douglas Staiger, Rebecca Thornton, Ebonya Washington, and anonymous referees for valuable input. We gratefully acknowledge support from the Smith Richardson Foundation and the Institution for Social and Policy Studies at Yale University. The views expressed herein are those of the author(s) and do not necessarily reflect the views of the National Bureau of Economic Research.

(C) 2007 by Justine S. Hastings and Jeffrey M. Weinstein. All rights reserved. Short sections of text, not to exceed two paragraphs, may be quoted without explicit permission provided that full credit, including $(\odot$ notice, is given to the source. 
Information, School Choice, and Academic Achievement: Evidence from Two Experiments Justine S. Hastings and Jeffrey M. Weinstein

NBER Working Paper No. 13623

November 2007, Revised February 2008

JEL No. D83,H0,I2,I28

\begin{abstract}
$\underline{\text { ABSTRACT }}$
We analyze two experiments that provided direct information on school test scores to lower-income families in a public school choice plan. We find that receiving information significantly increases the fraction of parents choosing higher-performing schools. Parents with high-scoring alternatives nearby were more likely to choose non-guaranteed schools with higher test scores. Using random variation from each experiment, we find evidence that attending a higher-scoring school increases student test scores. The results imply that school choice will most effectively increase academic achievement for disadvantaged students when parents have easy access to test score information and have good options to choose from.
\end{abstract}

Justine S. Hastings

Yale University

P.O. Box 208264

New Haven, CT 06520-8264

and NBER

justine.hastings@yale.edu

Jeffrey M. Weinstein

Yale University

P.O. Box 208268

New Haven, CT 06520-8268

jeffrey.weinstein@yale.edu 


\section{Introduction}

Several urban public school districts are currently experimenting with public school choice plans, and the federal No Child Left Behind Act (NCLB) of 2001 includes a choice provision allowing students in failing schools to choose to attend non-failing schools outside of their neighborhood. The goal of these choice plans is to increase academic outcomes for disadvantaged students by allowing them to attend higher-performing schools and by creating pressure on failing schools to improve through the threat of losing students, implicitly assuming that parents select schools for academics when offered the opportunity to do so. However, recent work on parental choice has found that low-income families place much less weight on academics when choosing schools, decreasing the immediate academic gains for those exercising choice (Hastings, Kane, and Staiger 2007), as well as the pressure for low-performing schools to improve academic achievement (Hastings, Kane, and Staiger 2006). ${ }^{1}$

It may be the case that, all else equal, low-income families place lower weights on school test scores because they rationally expect lower returns to education for their children. Alternatively, these families may place a high value on academic outcomes but find it more costly to act on those preferences, leading to lower expressed preferences for academic achievement. Several recent papers have explored how salience and cognitive costs affect consumer decisions in a wide-range of markets, including retail purchases, Medicare plans, credit cards, and retirement investments (Chetty, Looney, and Kroft [2007], Kling et al. [2008], Ausubel [1991], Hastings and Tejeda-Ashton [2008], respectively). If lower-income families face higher costs of gathering and interpreting statistics on academic achievement, they may choose schools based on easier-todetermine characteristics such as proximity, instead of school test scores.

\footnotetext{
${ }^{1}$ In addition to these papers, Schneider and Buckley (2002) monitored the search behavior of parents on an Internet web site for public schools in Washington, DC, and show that academics are more important search criteria for college-educated parents. Fossey (1994) and Armor and Peiser (1998) studied the characteristics of school districts' gaining and losing students in a Massachusetts interdistrict choice program and find that non-minority students and students with high-test scores were more likely to change districts. On the other hand, Jacob and Lefgren (2007) examined parental choices of individual teachers within schools and find that higher-poverty and minority parents are less likely to actively select a teacher, but conditional on choosing a teacher, parents in higher-poverty and minority schools place more emphasis on measures of teachers' ability to raise achievement, rather than student satisfaction.
} 
If this is the case, policy interventions that reduce the cost of acquiring and analyzing comparative information on school academic achievement may result in more parents choosing higher-performing schools within a public school choice plan. ${ }^{2}$ This paper uses a natural experiment and a field experiment in the Charlotte-Mecklenburg Public School District (CMS) to examine the degree to which transparent and easily accessible information on school-level academic performance impacts the schools that parents choose for their children, the importance they place on academic achievement when choosing schools, and the impact that attending higher-performing schools has on subsequent student outcomes.

Each spring since 2002 parents in CMS could submit their top three school choices for their children for the next school year. In order to find information on schools, they could reference a 100-plus-page school choice guide with self-descriptions of the positive aspects of each school. However, to access objective statistics on student achievement, parents would have to search the CMS website and make a comparison school by school. In the summer of 2004, after the annual school choice process had been completed, CMS re-sent choice forms along with a three-page spreadsheet printout of test scores at every school in the district (sorted alphabetically by name) to each family with a child enrolled at an NCLB-sanctioned school in order to comply with NCLB regulation. ${ }^{3}$ We use this implementation of NCLB as a natural experiment, comparing the choices parents made in the spring with no direct test score information to the choices they made in the summer with the NCLB-mandated test score information, to estimate the impact of information on parents' school choices.

We then analyze data from a field experiment we conducted during the 2006-2007 school choice process. Working with CMS, we provided information sheets with the school choice forms to parents with children in randomly selected schools serving primarily low- to middle-income neighborhoods. ${ }^{4}$ The sheets provided either clear statistics on academic achievement for each school in the child's choice set or information on academic achievement coupled with estimated

\footnotetext{
${ }^{2}$ Making information more salient can be represented as lowering decision-making costs in the terminology of Chetty, Looney, and Kroft (2007).

${ }^{3}$ This was the first year that any school could be categorized as “Title I improving” under NCLB in CMS. Each state completed a Consolidated State Application Accountability Workbook for NCLB, and states may have varied in the specifics of how they would implement the broad goals of the regulation. In Section III we will outline how Title I status and AYP are determined in the state of North Carolina and in CMS.

${ }^{4}$ We will discuss restrictions placed on the field experiment by CMS in Section IV.
} 
odds of admission. The information presented was simpler than the NCLB-mandated information in that it appeared in a one-page format, was sorted by the academic ranking of schools (instead of alphabetically), and contained only information on the schools relevant for the child's choice (e.g., only elementary schools for elementary school children). The simplified information was given to students at unsanctioned schools, where the control group received no direct information on test score performance, as well as at NCLB-sanctioned schools where the control group received the NCLB-mandated three-page spreadsheet. This allows us to estimate the impact that the simpler one-page format had over no direct information, as well as the added impact it had over the NCLB-mandated information.

In both of these experimental settings, we find that providing parents with direct information on school test scores resulted in significantly more parents choosing higher scoring schools for their children. Both the three-page NCLB-mandated information and our one-page information format increased the proportion of parents choosing non-guaranteed schools by 5 to 7 percentage points and increased the average test score of schools chosen by 0.05 to 0.10 student-level standard deviations, relative to the control group that received no direct information on test scores. We do not find evidence that our simpler one-page format had substantial added impact over the NCLB format, suggesting that gains from simplified information flatten out eventually.

The overall impact of receiving information on the test score of the school chosen represents the average impact of receiving information across parents who still chose their guaranteed school (zero impact) and parents who selected schools with significantly higher test scores. For example, the $16 \%$ of parents who responded to NCLB-mandated information in 2004 by choosing an alternative school chose schools with 0.5 student-level standard deviations higher test scores than the schools they had chosen in the spring. In both settings, we find that a key predictor of both responding to information by choosing an alternative school and the test score of the school chosen is proximity to high-scoring school alternatives. This is consistent with a model where parents choose schools to maximize utility, which is increasing in expected academic achievement but decreasing in time and travel costs, and implies that, even with transparent information, school choice can only be as effective as the options offered to parents. 
Next, we examine if an increase in the test scores of the schools parents chose led to improvements in their children's own academic performance. We use instrumental variables approaches, exploiting random variation generated by each experiment in the test score of the school attended to estimate the impact of attending a higher-scoring school on student academic outcomes. In both experiments, we find large but marginally significant impacts of the test score of the school attended on own test scores. The point estimates imply gains in own test scores of 0.37 - 0.41 student-level standard deviations from attending a school with a one standard deviation higher average test score. We compare our findings to those from prior studies that have examined the impact on own achievement of attending a school with higher average test scores in the context of choice without simplified information (Cullen, Jacob, and Levitt 2006; Cullen and Jacob 2007; Hastings, Kane, and Staiger 2007) and in the context of student assignment without choice (Hoxby and Weingarth-Salyer 2005; Hastings and Weinstein 2008).

\section{Background Description of the CMS School Choice Plan}

Before the introduction of a school choice plan in the fall of 2002, the Charlotte-Mecklenburg Public School District (CMS) operated under a racial desegregation order for three decades. For the 2002-2003 school year, CMS moved to a district-wide school choice plan in response to a court order to cease busing for racial integration. In the spring of 2002, parents were asked to submit their top three choices of school programs for each child. Each student was assigned a "home school” in her neighborhood. This school was typically one of the closest schools to her, and she was guaranteed admission to this school. Admission to non-guaranteed schools was granted based on a lottery. In the initial implementation of the school choice program, CMS underwent a large redistricting of home school assignments; approximately $50 \%$ of parcels lost property rights to the school they had rights to under busing.

In the first year of choice, the district required every parent to submit a choice form, and it achieved a 95\% compliance rate. In each year after the initial choice year, only parents of students in rising grades $\left(K, 6^{\text {th }}, 9^{\text {th }}\right)$, new students to the district, students affected by the opening of new schools, and parents who wished to change their children's school were required to submit choice forms. Each year a significant fraction of schools in the district is 
oversubscribed. ${ }^{5}$ The lottery process for assigning students to oversubscribed schools has continued since the introduction of school choice in 2002. Under the lottery system, students are first assigned to priority groups by school and grade. The priority groups have varied from year to year but generally have given priority to higher-poverty and lower-performing students who choose lower-poverty and higher-performing schools. ${ }^{6}$ Within each priority group, admission is determined by randomly assigned lottery number alone.

In order for parents to determine which schools to choose, CMS provided several resources. First, each year CMS produced a school choice guide that was approximately 100 pages long. It contained detailed instructions on how to complete the school choice form and how to submit it, along with a brief description of the lottery process. ${ }^{7}$ The bulk of the choice book was devoted to written descriptions of each school and program, from pre-school through high school. There are approximately 120 elementary, 40 middle, and 30 high school choice options in the district. The descriptions were written by the schools, describing the positive features each school offered to students. Objective measures of school characteristics, such as average test score performance, suspension rates, or racial compositions, were not included.

In addition, CMS provided a Family Application Center that parents could phone or visit in order to ask questions about the school choice process. The staff members at the Family Application Center emphasized the positive aspects of each school during their discussions with parents. In particular, staff members were supposed to respond to questions like "Which school is the best school?” by advising parents to discuss with their children what their needs were and then to visit the different school options in order to determine which school was the best for their children, since what a "good" school is depends on each individual child. ${ }^{8}$ It is important to note that this

\footnotetext{
${ }^{5}$ In the first year, approximately one third of the schools were oversubscribed due to CMS's commitment to expand capacities at schools in an effort to give parents one of their three choices. In subsequent years, two thirds of the schools have been oversubscribed as capacities were fixed.

${ }^{6}$ The priority group definitions were initially based on free- and reduced-lunch status and the concentration of freeand reduced-lunch recipients at a school. Since the use of lunch recipient status has recently received negative attention, CMS moved to use test score performance as a priority instead. Students performing below average on end of year exams are given priority for admission to schools performing at or above the district average on standardized exams.

${ }^{7}$ Parents were not told how the lottery was run (e.g., first-choice maximizer) or how the "priority boosts" were implemented.

${ }^{8}$ Information from interviews and conversations with Family Application Center staff.
} 
advice may be correct, as the relationship between school average test scores and student achievement has not been strongly established. However, it suggests to parents that identifying a "good" school takes a substantial and potentially daunting investment of time and effort.

CMS also offers an extensive website. On this website, parents can review objective statistics for each school. Individual "school profile" pages provide statistics, such as physical locations, standardized test score performance, suspension rates, racial compositions, and attendance rates. Parents would have to view statistics for each school separately; hence, obtaining objective information on schools might involve a significant web search and comparison.

On top of this information regime, two exogenous changes in information on school test scores were introduced: NCLB-mandated information in 2004 and our field experiment in 2006. Begining in 2004, families with children at NCLB-sanctioned schools were provided with NCLB-mandated information, which consisted of a three-page, alphabetically sorted printout of test score performance for every school in CMS (regardless of grade level). Our experiment in 2006 provided a one-page table of test scores, sorted by score, for only relevant choice options to students at both NCLB-sanctioned and unsanctioned schools. Figure I presents a timeline of events for reference throughout the discussion of the two experiments and empirical results. It is important to note that both experiments exclude the highest-income families in CMS; this is by definition in the case of NCLB and by stipulation in the case of our field experiment. ${ }^{9}$ Table I gives average characteristics of each experimental group, relative to the district-wide average. While families in both experiments are more likely to be African American, receive lunch subsidies, and have children with lower average test scores, these families are representative of families that many school choice plans, and NCLB in particular, are intended to help.

\section{NCLB - A Natural Experiment in Transparent Information on Academics}

Beginning in the summer of 2004, CMS began the first phase of sanctions for Title I schools that failed to make Adequate Yearly Progress (AYP) for two years in a row. As defined by CMS, a school is a Title I school (receives federal Title I funds) if $75 \%$ or more of its students qualify for

\footnotetext{
${ }^{9}$ We will discuss the design of the field experiment in detail in Section IV.
} 
federal lunch subsidies. As defined by North Carolina under NCLB compliance, a school needs to satisfy certain academic targets for ten subgroups of students in order to make AYP. ${ }^{10}$ If just one target was missed for one subgroup, then the school failed to make AYP. Thus if a school is both Title 1 for two years in a row and also fails to make AYP for two years in a row it is classified as Title 1 Improving and thus subject to NCLB regulation. ${ }^{11}$

Sixteen schools satisfied both constraints in 2004 and entered into regulation under NCLB. The regulation mandated that parents be notified of the NCLB status of their school and offered the choice to attend an alternative school. In addition, parents had to be given information on the academic achievement at the schools they could select. ${ }^{12} \mathrm{CMS}$ provided a three-page spreadsheet printout, sorted by school name, with the percent proficient for every school in the district, as well as a list of Title I Improving schools, since students exercising choice under NCLB are not allowed to choose another Title I Improving school. Thus, the NCLB legislation provided clear statistics to parents on the academic achievement at their school and at every other school in the district, as well as notification that their school had failed to meet AYP. ${ }^{13}$ For families with children at these schools, we observe the choices they submitted in the Spring 2004 choice plan with no direct information on school test scores and the choices they submitted in July 2004 after receiving the NCLB-mandated test score information. Students of parents who chose alternative schools in July were then entered into a school choice lottery.

Parents were told, just like in the regular spring lottery, that if they wanted to remain at their current school, they did not have to fill out a form. Of 6,695 students in our sample who received

\footnotetext{
${ }^{10}$ For a list of subgroups and detailed description of AYP targets and requirements, please see the Consolidated State Application Accountability Workbook for North Carolina (2005), which provides federal NCLB guidelines along with North Carolina's implementation of these guidelines.

${ }^{11}$ Schools that satisfied either the Title I requirement or the AYP requirement, but not both, were not subject to regulation under NCLB. For example, thirteen schools were Title I in both the 2002-2003 and 2003-2004 school years but made AYP in at least one of those years and hence were not subject to regulation under NCLB. Similarly, 21 schools did not make AYP in either of the two school years but were not Title I and thus were not subject to regulation under NCLB.

${ }^{12}$ United States Department of Education, Public School Choice. (Washington, DC: United States Department of Education, 2004). Available at www.ed.gov/policy/elsec/guid/schoolchoiceguid.pdf. p. 18.

${ }^{13}$ Importantly, this information is only provided to parents of students slated to attend a NCLB school in the subsequent school year.
} 
NCLB notification, 1,149 responded by submitting a form in July. ${ }^{14}$ Of the parents who did fill out a form in July, 57 of them listed their current NCLB school as their first choice, which they did not need to do in order to remain at their NCLB school. Thus, 1,092 parents filled out a form in July and chose a school different than their current NCLB school.

Given the number of responders alone, it appears that NCLB notification had a significant impact on parental choice. Table II presents mean choice behavior for parents at NCLB schools before and after receiving NCLB-mandated information. If we include all parents (those that chose their NCLB school in the spring choice round and those that did not), we see that, after receiving NCLB information, the fraction of parents that chose an alternative school increased by 5.1 percentage points relative to a base of $11 \%$. The average test score of the school chosen increased by a statistically significant 0.047 student-level standard deviations. If we consider only parents who chose their NCLB school first in the spring, the fraction of parents choosing an alternative school increased from $0 \%$ to $14.5 \%$. The average test score of the school chosen increased by 0.088 student-level standard deviations.

The average difference in the test score at the chosen school between the spring and the summer implies that parents who submitted forms in the summer chose schools with much higher average test scores. Figure II shows a kernel density estimate of the difference in the test score of the first-choice school in July and the NCLB school for parents who did not choose the NCLB school first in July. On average, responders selected first-choice schools with 0.62 student-level standard deviation higher test scores than the NCLB school. A small fraction of parents chose schools that were close to or slightly worse performing than the NCLB school, while another minority of parents chose some of the highest-performing schools in the district; schools that outperformed the NCLB school by over one student-level standard deviation in test score.

Rows 1 and 2 of Table III show the average test score at the first-choice school in the spring versus in July for parents who chose an alternative school in July. They indicate a 0.485 (-0.017

\footnotetext{
${ }^{14}$ We began with the 8,284 students who received NCLB notification, of which 1,363 responded by filling out a form in July. We exclude from the analysis students who were not active in CMS at the time of the spring lottery (221 students), students with special needs or those being retained (1,245 additional students), and students who had missing demographic information (123 additional students).
} 
versus -0.502) student-level standard deviation increase in the average test score of the school chosen after receiving the NCLB-mandated information. This change in choice behavior was not mechanically generated by the fact that NCLB parents could not select another NCLB school in July. Rows 3 and 4 demonstrate this point. These rows show that the average test scores of available schools within five miles only increased by 0.075 (-0.247 versus -0.322$)$ student-level standard deviations by excluding other NCLB schools from the choice set. Hence if parents chose schools at random from the set of schools within five miles in the spring and in july, we would expect only a 0.075 increase in average score of the school chosen. Hence almost all of the gain in the average test score of the chosen school came from a change in choice behavior.

Table IV examines which types of parents were more likely to respond to NCLB-mandated information by choosing an alternative school, and of those parents, which ones were more likely to choose higher-scoring schools. Suppose that, once a parent is fully informed about the academic performance at each choice option, they select a school to maximize utility which is increasing in expected academic achievement but decreasing in commuting costs to schools. Simplified information on test scores may lower information costs, increasing the implicit weight parents place on academics when choosing a school. However, parents may still face trade-offs from time and transportation costs that censor the impact of information on observed choice behavior. We might expect to see the largest impact of information on parental choice where these other costs of choosing a school are lowest, for example, where there are proximate highscoring school alternatives.

Table IV presents regressions of the form:

$$
y_{i}=\alpha+X_{i}^{\prime} \beta+R_{i}^{\prime} \delta+\varepsilon_{i}
$$

where $y_{i}$ is an indicator for whether the parent chose an alternative to their NCLB school (columns (1) and (2)) or the average test score at the first-choice school conditional on having chosen an alternative school in July (columns (3) and (4)), $X_{i}$ is a vector of student characteristics, $R_{i}$ are NCLB school and program fixed effects, and $\varepsilon_{i}$ is a random error term that allows for clustering at the NCLB school-program and grade level. Columns (1) and (3) present results for the entire sample, while columns (2) and (4) present results for the sub-sample of families who chose their NCLB school in the spring. 
The results imply that proximity to high-scoring schools with one student-level standard deviation higher test scores increases the probability of responding to information by choosing an alternative school by 9.1 - 11.0 percentage points (columns (1) and (2)). Columns (3) and (4) show that, conditional on choosing an alternative school, parents with higher-scoring schools within five miles choose significantly higher-scoring alternatives $(0.186-0.233$ student-level standard deviation increase). Although the average score of and distance to schools within five miles are relatively ad hoc measures of choice set characteristics, they do have the impact on choice behavior we would expect to see if parental choice response to simplified information were constrained by factors that affect the cost of choosing high-performing schools.

In addition to choice set characteristics, demographic characteristics are also significant determinants of the response to information. Both parents with a single child in CMS and parents of rising-grade children were more likely to choose out in July; however, conditional on choosing out, they did not choose significantly higher-scoring schools. ${ }^{15}$ This is consistent with the hypothesis that these characteristics may lower the costs of choosing an alternative school, but they may not be associated with a higher implicit value for academic achievement. African American parents were more likely to choose out in July; however, conditional on choosing out, both African Americans and parents of free-and-reduced lunch recipients selected significantly lower performing schools. ${ }^{16}$ Interestingly, both high-scoring students and those with past suspensions were more likely to choose out in July. While high- and low-performing students sought to attend alternative schools, conditional on choosing out, test scores and suspension rates had no significant effect on the test score of the school chosen. Unexcused absences, on the other hand, decrease significantly the probability of choosing out, as well as the test score of the school chosen, although the magnitudes of the coefficients are small. As we might expect, the regression results in columns (1) and (3) also show that parents who chose out in the spring were

\footnotetext{
${ }^{15}$ We define a student as a single child if there are no other children registered in CMS with the same last name and street address. While this may not capture all siblings, it at least captures those for whom schooling decisions are made from the same residential address and within the same family unit. It is also the definition used by CMS when defining sibling status. Rising grade students are those who going into Kindergarten, $6^{\text {th }}$, or $9^{\text {th }}$ grade and will therefore be changing school locations for the next school year as they transition to the next education level.

${ }^{16}$ This may reflect the trade-off between school average test score and fraction minority that African American parents face when choosing a school. However, it is important in interpreting these results to remember that this sample of students is almost $90 \%$ lunch subsidy recipients and over $77 \%$ African American.
} 
also significantly more likely to choose out in July and, conditional on choosing out, selected higher-scoring schools.

Overall, the NCLB-mandated information facilitated the choice of a higher-performing alternative school for a significant fraction of parents. Importantly, we find that proximity to high-performing schools is a key factor in determining the probability of responding to information by choosing an alternative, higher-scoring school.

\section{A Field Experiment in the 2006-2007 School Choice Plan}

Working with CMS, we designed simplified information sheets to attach to parents' school choice forms for the 2006-2007 school choice round to test if simplified information has a similar effect on parental choice outside of the NCLB sub-population and also if moving to a simpler one-page format has an added impact over the three-page NCLB-mandated test score information. The field experiment was limited by the district in several important ways. First, students attending the same school and living in the same choice zone had to receive the same type of information. Hence, information was randomized at the school and choice-zone level (school-zone). ${ }^{17}$ Second, the set of schools was restricted to NCLB schools and non-NCLB schools serving low- to middle-income neighborhoods, and we were asked to limit the number of forms provided to non-NCLB students to a few thousand. As in prior years, choice forms were provided to all students slated to attend NCLB schools (to comply with the choice requirements of the law), to rising grade students (going into Kindergarten, $6^{\text {th }}$, or $9^{\text {th }}$ grade in the next school year), and to students whose home-school assignments for the 2006-2007 school year were affected by the opening of new schools. Our simplified information sheet was attached to this choice form, so grade restrictions held as well.

\footnotetext{
${ }^{17}$ The district was split into 4 quadrants called “choice zones”. Parents could choose from any school in the district, but their child would only receive free transportation to schools in their choice zone. For the 2006-2007 school year, CMS significantly redrew the boundaries of the choice zones so that each zone contained a range of possible schools given the new restricted choice set. Hence, it was often the case that students attending the same current school lived in different 2006-2007 choice zones, even though they would have been in the same choice zone under the prior choice zone boundary definition. In addition the randomization was done separately for school-zones in 11 randomization blocks created from high-school feeder zones to make sure that treatments were geographically spread since we had relatively few observations to randomize over.
} 
In addition, we were restricted to providing information on test scores and odds of admission. After the first year of school choice, a significant number of schools in the district were oversubscribed, admitting few, if any, students each year. Despite this fact, demand for these schools did not decline. ${ }^{18}$ We combined odds of admission with test scores to examine how, if at all, parents would react to clear information on admit chance. We randomly selected school-zones to receive either Score forms (test score information only) or Odds forms (test scores coupled with odds of admission) subject to the constraints listed above. The randomization was done separately for each of the segments of schools: pre-K (rising kindergarten), $5^{\text {th }}$ graders (rising $\left.6^{\text {th }}\right), 8^{\text {th }}$ graders (rising $9^{\text {th }}$ ), and NCLB students. There were 6,328 non-NCLB students in 46 school-zones (39 schools) who were part of the field experiment, and 10,134 NCLB students in 31 school-zones (19 schools). ${ }^{19}$

The simplified information forms were specialized for each child. They contained a list of schools in the student's choice set, which depended on the student's choice zone and her home school assignment for the 2006-2007 school year. Figures III and IV provide examples of the simplified information forms. The forms list the schools in the choice set, along with programspecific school average scores (and odds of admission where applicable). ${ }^{20}$ The scores were calculated from the prior year's average performance of students in that school and program on standardized tests and then re-scaled to correspond to a percentage score that looks like a grade. ${ }^{21}$

\footnotetext{
${ }^{18}$ This led the district to limit the available schools for choice in the 2006-2007 school choice plan to those with a positive probability of admitting students, in order to mitigate parental discontent. Despite the change in the schools offered for choice, there were many school options with a wide range of academic performance for families to choose from. For further discussion of the 2006-2007 school choice plan, what information the district provided on school capacity constraints, as well as summary statistics on the 2006-2007 school choice offerings, please see Hastings, Van Weelden, and Weinstein (2007).

${ }^{19}$ Note that the number of NCLB schools increased since 2004; however, they were all still elementary and middle schools. There were nineteen NCLB schools expected for the 2006-2007 school year. After the 2006 test score results were completed in July 2006, two more schools ended up being classified as Title I Improving, resulting in 21 total NCLB schools for the 2006-2007 school year.

${ }^{20}$ Two types of each form were given: one with only numeric information on test scores and one with a graphical apple rating that represented the numeric scores in addition to the numbers themselves. The graphical addition was randomized within school and homeroom, since it technically added no new information. We did not find that further simplification affected choices, so we pool the choice forms with and without graphics for this analysis.

${ }^{21}$ The schools in each information table were sorted by test score. The guaranteed school option for each child was presented separately in its own line below the test score table. This was done to facilitate personalizing the information sheets for each child and to match the way the choices were listed on the actual choice form. Typically, the guaranteed choice was open to lottery choices, so it would be listed in test-score-order within the table as well. However, in some instances where the guaranteed choice was not open for students to choose in, it only appeared as a separate line below the choice table. This was the case, for example, in Figure IV but not in Figure III.
} 
The odds of admission were calculated based on the prior year's admission rates. The information sheets incorporated the CMS logo and its graphic themes and were designed to look as if they were made by and came from the school district. The school district approved the final design. The staff at the Family Application Center reported seeing parents with their simplified information sheets in hand, with notes written on the forms as they made their decisions.

Tables $\mathrm{V}$ and VI examine the effect that simplified information had on aggregate choice behavior. The outcome measures of interest are aggregated or averaged at the school-zone level, that is, the level at which the treatment was assigned. Table V shows that average baseline characteristics are balanced across treatment and control groups. The first three columns give the means of the dependent variables (baseline characteristics) for the treatment and control groups. The last two columns give the coefficient from a regression of each dependent variable on whether the school-zone received Score or Odds forms, controlling for randomization-block fixed effects: $:^{22}$

$$
\bar{y}_{S}=\alpha+\theta T_{S}^{1}+\phi T_{S}^{2}+R_{S}^{\prime} \delta+\varepsilon_{S}
$$

where $\mathrm{T}_{\mathrm{S}}{ }^{1}$ and $\mathrm{T}_{\mathrm{S}}{ }^{2}$ are indicators for whether students in school-zone $S$ received the Score form or the Odds form, respectively, and $R_{S}$ are randomization-block fixed effects. All of the coefficients are insignificant, implying that baseline characteristics are balanced across treatment and control groups.

Table VI presents regression results from specification (2), where the dependent variables are the fraction of parents listing a non-guaranteed school as their first choice and the average difference between the test score of the first-choice school and the test score at the guaranteed school (test score gain). Panel 1 presents results pooled across non-NCLB and NCLB school-zones. Panels 2 and 3 present results separately for non-NCLB and NCLB school-zones, respectively, since the information available to the control groups differs across those two samples. Within each panel, the first two rows report the treatment effect of receiving a Score form or an Odds form, while the third row presents the pooled treatment effect of receiving either type of form. Columns (1) and (2) provide ordinary least squares estimates, while columns (3) and (4) provide weighted

${ }^{22}$ Because the randomization was done separately within the different grade levels for non-NCLB schools and zones, and since class sizes vary across these zones, we control for randomization-block fixed effects (Rouse 1998). 
least squares estimates, where each school-zone observation is weighted by the number of students in that school-zone.

The first panel of estimates shows no significant overall impact of transparent information on parental choice behavior pooled across the non-NCLB and NCLB observations. However, the second panel shows that among the non-NCLB school-zones, where the control group received no direct information on test scores, information had a significant impact on choices. Receiving information on test scores increased the fraction of parents who chose a non-guaranteed school by about 7 percentage points, off of a base of 31\%. This implies that simplified information on test scores increased demand for non-guaranteed schools by an economically significant $23 \%$. Receiving information on odds of admission and test scores did not have a significant impact on the fraction of parents choosing non-guaranteed schools, although the point estimates are similar in magnitude to the point estimates on Score form. ${ }^{23}$ Both forms have similar effects on the average difference between the test score of the first-choice school and the test score at the guaranteed school; Score forms and Odds forms caused an increase of about 0.10 student-level standard deviations (a 70\% increase relative to the mean of 0.14 ). If we pool the receipt of a Scores or an Odds form into one indicator for received information, the overall impact on parental choice is similar and slightly more significant. Hence, in the non-NCLB group, parents respond to information by choosing alternative schools with significantly higher test scores.

These results are similar in magnitude to the results in Table II from the 2004 NCLB natural experiment. This suggests that our information may have no additional effect over the NCLBmandated information. Indeed, the third panel of results in Table VI presents estimates of the effects on aggregate choice behavior in the NCLB sample of school-zones. Here the control group received the three-page NCLB-mandated information; insignificant results imply that our simplified information had no effect above and beyond the NCLB-mandated information. This suggests that the impact of providing easy-to-access and transparent information flattens out

\footnotetext{
${ }^{23}$ Hastings, Van Weelden, and Weinstein (2007) find that simplified information on test scores also affected the average number of choices that parents listed. School-zones receiving Score forms had a significant $24 \%$ increase in the average number of choices listed, relative to the control group. However, school-zones receiving Odds forms had no significant average increase in the number of choices listed relative to the control group. This implies that knowing the odds of admission along with the test score of each choice decreased the number of choices listed relative to receiving information on test scores alone.
} 
eventually, and most of the effect on choices may come from providing clear statistics at the time of choice, rather than the exact format those statistics appear in. ${ }^{24}$

As in the 2004 NCLB natural experiment, we can use student-level data to examine which families were more likely to respond to our information sheets by choosing substantially better schools. Figure V shows a kernel density estimate, by treatment and control groups, of the test score of the school chosen relative to the guaranteed school for parents who chose alternative schools. Because mean impacts of scores and odds were similar, we combine the treatments into “Received_Information” and plot the choices of those families versus the choices of control group families. There are two interesting things to note. First, receiving information almost eliminates the density of parents who pick schools with lower average test scores than their guaranteed option (density to the left of zero). Second, receiving information more than doubles the density of parents choosing schools with average test scores more than one student-level standard deviation higher than their children's guaranteed school. This gain represents moving from a school in the lower quartile of the distribution of test scores across schools to one in the upper quartile.

Table VII presents results for the non-NCLB sample from regressions of the form:

$$
y_{i}=\alpha+\theta T_{i}+T_{i} Z_{i}^{\prime} \lambda+X_{i}^{\prime} \beta+R_{i}^{\prime} \delta+\varepsilon_{i}
$$

where $\mathrm{X}_{\mathrm{i}}$ is a vector of student characteristics such as race and lunch recipient status, as well as characteristics of the student's choice set that might affect her choices, such as the average test score at local schools and the average distance to local schools. The $R_{i}$ are randomization-block fixed effects. We combine the forms into one treatment for "received information", $T_{i}$, which is an indicator for whether the child received a Score form or an Odds form, and $Z_{i} T_{i}$ is a vector of interactions between baseline characteristics and the treatment indicator. Standard errors are clustered at the school-zone and grade level.

Column (1) shows the interaction effects of receiving information on the gain in the score of the first-choice school relative to the guaranteed school, and column (2) shows the same regression

\footnotetext{
${ }^{24}$ Alternatively, it may be the case that this group of parents is relatively inert. Parents who would have responded to NCLB information and notification may have already responded by choosing out in prior years. Hence the remaining students have parents who are not responsive to information on academic outcomes.
} 
restricted to the sample of students that chose a non-guaranteed school. Both columns show that the average impact of receiving information on the score of the school chosen is significantly increasing in the average test score of schools within five miles, implying that simplified information will have the largest impact on observed choices where the cost of choosing higherscoring schools is lowest. These results are similar to the results found using the 2004 NCLB natural experiment and emphasize that, while simplified information may have a large impact on the implicit weight parents place on academics, this impact will only be expressed through changes in observable choice behavior for families whose costs of choosing good schools, once they can identify them, are relatively low. ${ }^{25}$

Among the interactions with demographics, we again find that parents of children with no other identifiable siblings in CMS were more likely to respond to information by changing their choice behavior. This may be because these families face fewer transportation constraints that may inhibit them from sending a child to a non-guaranteed school or a school that is further away. ${ }^{26}$ We also find that African American parents are more likely to respond to transparent information by choosing higher-scoring schools. The opposite was true in the 2004 NCLB natural experiment, where African Americans and free-lunch recipients who selected alternative schools in response to NCLB information chose slightly lower-scoring schools than other responders. There is much more variation in socio-economic status in this sample than in the 2004 NCLB natural experiment, which may generate the difference in results.

Taken together, the results from the 2004 NCLB natural experiment and the field experiment we conducted in 2006 imply that receiving transparent information on school academic achievement has a significant impact on parental choice. It increased demand for non-guaranteed schools, as

\footnotetext{
${ }^{25}$ Hastings, Van Weelden, and Weinstein (2007) estimate the impact that simplified information had on the implicit weight placed on academics in a random-utility model of school choice. They find that information doubled the importance placed on test scores, a change in expressed preferences equivalent to that of a $\$ 65,000$ increase in family income. Using these preference estimates, they simulate the change in demand for non-guaranteed schools if the entire sample were given simplified information. They find an 8 percentage point increase in demand, very similar to the reduced-form treatment effect identified in Table VI. The random utility model incorporates the characteristics of each family's choice set, such as distance to each school and distance to the guaranteed school. Thus a very large impact on preferences for academics may only results in an 8 percentage point increase in demand, due to the fact that families still face other trade-offs, such as relative transportation costs, when choosing a school. Our measure of average distances and test scores of schools within five miles is a reduced-form way of capturing these trade-offs.

${ }^{26}$ All students in this setting are rising-grade students, so we cannot include an indicator for rising-grade students.
} 
well as the test scores of the schools families chose. The fact that overall results were similar across the two experiments suggests that the degree of simplification is not as important as just providing information on school test scores to parents at the time of choice. Furthermore, across the two samples, families with high-scoring schools in close proximity are the most likely to choose better schools, as we would expect if parents face trade-offs between utility gains from academics versus proximity when choosing schools.

\section{Impact on Test Scores}

While simplified information on school test scores resulted in more parents choosing higherscoring schools, it is not clear if students benefit academically from attending those schools. A handful of recent papers have examined the impact of attending first-choice schools on academic outcomes using lottery assignments in school choice plans to generate random variation in the test score at the school attended. ${ }^{27}$ Cullen, Jacob, and Levitt (2006) examine lottery outcomes for high school choice in the Chicago Public Schools, and Cullen and Jacob (2007) examine similar lotteries for elementary school students. Neither finds a significant impact of attending a firstchoice school on test scores. This may be in part caused by the fact that, on average, attending a first-choice school results in only small increases in the test score of the school attended (0.019 percentile points or about 0.1 student-level standard deviations). ${ }^{28}$ It also may be the case that parents are picking particular schools for different reasons, leading to heterogeneous treatment effects that average towards zero. Hastings, Kane, and Staiger (2007) use lottery assignments from the first round of school choice in CMS (Spring 2002) and find that parents pick schools for different reasons and that students of parents who place high implicit weights on academic achievement experience significant gains in test scores as a result of attending their first-choice school.

\footnotetext{
${ }^{27}$ Angrist, Bettinger, and Kremer (2006) examine a voucher program in Colombia that provided one half of secondary school tuition by lottery to low-income high school students. Continuation of the voucher after the first year was predicated on sufficient academic progress. They find significant impacts of winning a voucher lottery on graduation rates and other measures of academic performance.

${ }^{28}$ Cullen, Jacob and Levitt (2006) also examine subgroup impacts for students who picked high-performing schools. In that subgroup, winning a lottery increased the score of the school attended by 0.043 percentile points or about 0.18 student-level standard deviations. They do not find significant subgroup impacts on scores.
} 
The two experiments in this paper provide an opportunity to examine the impact of attending higher-scoring schools on own academic achievement for parents who were much more directed in choosing schools based on academic dimensions, as a result of receiving transparent information on test scores. ${ }^{29}$ The experiments have two slightly different designs, so we will analyze them separately. In the field experiment, we will focus on the non-NCLB students and instrument for the test score at the school attended with the random assignment of information and its interactions with baseline characteristics that lower the expected costs of responding to information by choosing a higher-scoring school. In the 2004 NCLB natural experiment, treatment and control groups were the same set of families before and after receiving NCLBmandated information, so we do not see eventual academic outcomes for both treatment and control groups, as we do in the field experiment. However, since students of parents who chose alternative schools were subjected to a lottery admission process, we can use the lottery assignments to generate random variation in the score of the school attended.

\section{Field Experiment: The effect of attending a higher-scoring school on test score outcomes}

Table VIII presents estimates from instrumental variables regressions of the test score of the school attended on student academic performance for the 2006-2007 academic year. We present results using both school-zone aggregate data and student-level data. Each column presents regressions of the form:

$$
\begin{gathered}
Y=\theta S+X \beta+\varepsilon \\
S=Z \Pi+v
\end{gathered}
$$

where the dependent variable, $Y$, is a vector of test score outcomes, $S$ is the endogenous average test score of the school attended in the 2006-2007 school year measured in student-level standard deviation units, $X$ is a matrix of covariates that include randomization-block fixed effects as well as student-level baseline characteristics in specifications using student-level data. Equation (5) specifies the test score of the school attended as a function of the exogenous regressors. The excluded instrument is receiving information, and in specifications using student-level data, we will add as additional instruments interactions between receiving information and baseline

\footnotetext{
${ }^{29}$ Using a random utility model, Hastings, Van Weelden, and Weinstein (2007) show that receiving information in the field experiment doubles parental preferences for test scores. Comparing mean preferences to those in Hastings, Kane, and Staiger (2007), we see that receiving information effectively turned low-preference-for-academics families into high-preference-for-academics families.
} 
characteristics that decrease the cost of attending a higher-scoring alternative school. Because standardized testing begins in third grade, we do not have outcome measures for kindergarteners, so we drop them from the analysis. This leaves us with 3,280 students in 33 school-zones. Limited Information Maximum Likelihood (LIML) results are reported for each specification. Standard errors are clustered at the school-program and grade attended for all specifications using student-level data.

The successive columns of the table show how the point estimates change with aggregation and the set of instruments used. The first column uses data aggregated at the school-zone level to examine the impact of the school-zone averaged score of the school attended on school-zone averaged test score outcomes. We instrument for the averaged score of the school attended using an indicator for whether the school-zone block received information. Because only $36 \%$ of students who chose alternative schools were admitted, receiving information is a weak predictor of the score of the school attended. ${ }^{30}$ The point estimate on the score of the school attended is 0.336 but highly insignificant, with a standard error of 0.550 . The p-value of the excluded instrument is only 0.09 . The second column reports results for the same specification in column (1) but uses student-level data and adds baseline student-level controls for academic achievement, demographics, and choice-set characteristics. The instrument is still weak, with a p-value of 0.10. The point estimate on the test score of the school attended (0.183) is similar to that in column (1) but remains highly insignificant with a standard error of 0.398 .

The third column has the same specification as column 2 but adds additional instruments that measure how easily a parent could choose a high-scoring alternative school. In particular, we include the average test score of schools within five miles and an indicator for whether the child is a single child in CMS, both interacted with receiving information. This increases the p-value of the excluded instruments to 0.04 , the point estimate increases to 0.355 , but it is not quite significant at the $10 \%$ level. The fourth column of Table VIII adds in the average distance to

\footnotetext{
${ }^{30}$ Once parents submitted their choice forms, admission to oversubscribed schools was granted based on a lottery process. Because of this lottery, only $36 \%$ of students were admitted to their first-choice school. Approximately the same fraction attended their chosen school. This comes both from students who won lotteries and attended their chosen school as well as students who were admitted off of waitlists into their chosen school over the summer as seats became available due to student mobility. Receiving information still increases the test score of the school attended versus the home school, but the effect is half of the magnitude for the score of the school chosen (0.05 instead of 0.10).
} 
schools within five miles and the distance to the guaranteed school, both interacted with receiving information, as further instruments to adjust for the degree to which a family might be relatively far or close to all of its school options. This increases the p-value of the excluded instruments to 0.01 and results in a significant point estimate for the score of the school attended of 0.409. This implies that increasing the score of the school attended by one student-level standard deviation results in an expected gain in own test score of about 0.4 student-level standard deviations. The estimated effect is large, but the standard errors are large as well, with 95\% confidence interval lower-bound of 0.017 .

\section{NCLB Natural Experiment: The effect of attending a higher-scoring school on test score outcomes}

The 2004 NCLB natural experiment provides a second opportunity to examine if there are academic gains for children of parents that chose substantially better schools in response to receiving transparent information on test scores. Because all families were treated with the NCLB-mandated information, we will use the summer 2004 random lottery admissions to chosen schools to create treatment and control groups.

Once choice forms were submitted in July 2004, admissions were determined by lottery. The lottery was run based on the number of seats made available for each grade and school-choice combination. The lottery number was the concatenation of two priority numbers followed by a random number. Priority was given to students performing below grade level and to students who qualified for free or reduced lunch, in order to satisfy the NCLB requirement that the lowest-performing and poorest students be given the first right to attend an alternative school. We will use only the priority group (if any) in each grade and choice combination for which some students won and some students lost that lottery; that is, we include only students for whom lottery number alone determined admission. This leaves us with a very small sample of 227 students, since many students were in priority groups for which everyone was either admitted or denied admission for that particular grade and choice. ${ }^{31}$

${ }^{31}$ For further discussion of the lottery process and the construction of this sample, see Hastings and Weinstein (2007). 
Table IX presents regression results of the form:

$$
y_{i}=\alpha+\theta w_{i}+L_{i}^{\prime} \delta+\varepsilon_{i}
$$

where $w_{i}$ is an indicator for whether student $i$ won the lottery to attend her chosen school and $L_{\mathrm{i}}$ is a vector of lottery fixed effects (Rouse 1998). The dependent variables are listed as rows in Table IX, and each cell reports the coefficient and standard error for $\theta$. Standard errors are clustered at the attended school program and grade level. The results show that winning a lottery to attend a chosen school had no significant impact on student baseline characteristics; however, it did significantly increase the probability of attending a chosen school by 0.60 and the score of the school attended by 0.34 student-level standard deviations. ${ }^{32}$

Table X presents instrumental variables regressions of the form:

$$
\begin{gathered}
y_{i}=\alpha+\theta S_{i}+X_{i}^{\prime} \beta+L_{i}^{\prime} \delta+\varepsilon_{i} \\
S_{i}=\mu+\phi w_{i}+\lambda w_{i} s_{i}+X_{i}^{\prime} \beta+L_{i}^{\prime} \gamma+v_{i}
\end{gathered}
$$

where $y_{i}$ is student $i$ 's combined test score outcome in student-level standard deviations; $S_{i}$ is the average test score of the school attended in the 2004-2005 school year measured in student-level standard deviation units; and $X_{i}$ is a vector of student baseline characteristics, including baseline test score, race, lunch status, and level effects for all included interactions. $L_{i}$ is a vector of lottery fixed effects. Excluded instruments are an indicator for whether the student won the lottery, $w_{i}$, and its interaction with the test score of the chosen school relative to the guaranteed school, $\boldsymbol{s}_{i}$. Standard errors are clustered at the school-program and grade attended.

The first column of Table $\mathrm{X}$ shows a large but insignificant impact of the test score of school attended on own test score outcomes when we use only indicator if the student won the lottery to attend her chosen school as an instrument. Column 2 adds the interaction of winning the lottery with the difference between the scores of the chosen school and guaranteed school as an additional instrument, allowing the treatment effect to vary with the size of the treatment. ${ }^{33}$ When we add this instrument, the coefficient on the score of the school attended increases in size

\footnotetext{
${ }^{32}$ In addition, the score of the school attended increases by about half the score of the school chosen, reflecting the fact that winning the lottery increases the probability of attending the chosen school by about $50 \%$.

${ }^{33}$ Note that this is a valid instrument since we control for lottery fixed effects, and lottery number is randomly assigned within each school choice lottery.
} 
and becomes marginally significant. The point estimate implies that attending a school with one student-level standard deviation higher test scores results in a 0.37 student-level standard deviation increase in own test scores. This result is similar in magnitude to the results from the 2006-2007 information field experiment and is marginally significant despite the small sample size.

Taken together, the results of these two experiments imply that providing clear information on school test scores within a choice plan increases the proportion of parents choosing higherscoring schools for their children. These changed choices appear to have generated measurable improvements in academic outcomes. ${ }^{34}$ The impact on own test scores for attending a school with higher average test scores is similar to the heterogeneous treatment effect that Hastings, Kane, and Staiger (2007) find for students whose parents selected schools with a strong implied preference for academics ('self-informed' parents). In their study, the impact of winning the school choice lottery for families in upper quartile of the preference-for-test-score distribution was 0.082 student-level standard deviations, and winning the lottery resulted in them attending schools with 0.16 student-level standard deviation higher average test scores (a 0.51 impact). ${ }^{35}$

It is important to note that these results do not imply that moving a random low-achieving child to a school with high average test scores will result in academic gains for that child. This study identifies the impact of the test score of the school attended off of parents who respond to school choice with information on test scores, through choosing an alternative school with an emphasis on academic achievement. ${ }^{36}$ Other recent studies have estimated the impact of moving a child to a school with higher average test scores using exogenous changes in school assignments generated by busing for integration programs (Hoxby and Weingarth-Salyer 2005; Hastings and Weinstein 2008). These studies find significant impacts of $0.16-0.25$ student-level standard

\footnotetext{
${ }^{34}$ In addition, average test score of the school attended is positively correlated with other school characteristics, such as attendance, safety, average peer income levels, and, potentially, teacher and staff quality. Thus, the impact on own academic outcome of moving from a low-performing school to a high-performing school should not be interpreted as the impact of test scores alone but rather of a potential bundle of school quality measures that are all correlated with higher average test scores. Future research may be able to determine the optimal type of information to provide to parents to increase test score outcomes.

${ }^{35}$ From author's calculations using predicted test score gains from results in Table X, row 2 of Hastings, Kane, and Staiger (2007) for the upper quartile of the preference-for-test-scores in the sample used for the lottery analysis.

${ }^{36}$ The results from Hastings, Kane, and Staiger (2007) can be seen as identifying the impact among families with high preferences for academics, that is, families who are informed and choose for academics on their own.
} 
deviations on own test scores from attending a school with one student-level standard deviation higher average test score. This suggests that the impact of attending a higher-performing school is larger for students of parents who are informed and seeking academics, than it is for an average student. Letting parents self-select and providing information so that they can make fully informed choices may be an important benefit of school choice over student assignment for a student's own academic outcome. ${ }^{37}$

\section{Conclusions}

The goal of a public school choice plan is to increase academic outcomes for disadvantaged students by allowing them to attend higher-performing schools and by creating pressure on failing schools to improve through the threat of losing students. This implicitly assumes that disadvantaged families are fully informed about school academic performance and choose higher-performing schools when offered the opportunity to do so. This paper used two experiments in a public school choice plan to show that information and decision making costs play important roles in parental choice among low-to-middle income families. Providing clear statistics on school test scores with parents' choice forms resulted in significantly more parents choosing higher-scoring schools for their children. The impact of information on observed choice behavior was largest for families with higher-scoring schools in relatively close proximity, implying that school choice and information are most effective when parents have quality alternatives within a reasonable distance. Using the random variation in the test score of the school attended generated by each experiment, we find evidence that attending a higherscoring school results in significant gains to own test score outcomes.

The results in this study suggest that simplified information on school academic achievement may have a significant impact on the efficacy of school choice plans for disadvantaged families. First, providing simplified information to families at relatively underperforming schools resulted in immediate academic gains from attending an alternative school. Second, because direct

\footnotetext{
${ }^{37}$ Notice that this does not imply that measures of overall student achievement will necessarily be higher under school choice. To understand this, one would need a model of achievement for each student who does not select a higher-performing school, as well as a supply-side model of school closures and openings as a district responds to choice by offering different products in order to maximize student achievement.
} 
information on school test scores increased the fraction of parents choosing higher-scoring alternatives, policies that incorporate simple and direct information on academics may increase pressure on under-performing schools to improve achievement through the threat of losing students. These results add to growing evidence that the provision and framing of information may be an important tool that policy makers can use when choice is introduced to increase efficiency in public goods markets (Choi, Laibson, and Madrian 2006; McFadden 2006; Winter et al. 2006; Hastings and Tejeda-Ashton 2008; Kling et al. 2008).

The results also highlight the potential problems with incentives to provide information. In private markets with a standard rating, firms have the incentive to disclose ratings since highrated firms will gain an increase in demand and low-rated firms will self-reveal if they do not post their ratings. ${ }^{38}$ In public schooling, high-quality providers may not have an incentive to voluntarily post their scores if they only attract uniformed parents whose children may be relatively more costly to educate than those of informed parents. ${ }^{39}$ Thus in such settings, incentives for voluntary advertising and disclosure may break down, potentially requiring additional incentive structures or mandates for information provision, as was the case for NCLB.

Yale University and National Bureau of Economic Research Yale University

\footnotetext{
${ }^{38}$ Mandatory disclosure and voluntary disclosure yield the same outcome, as long as the information is costlessly verifiable. Discussions of this information unraveling principle can be found in Grossman (1981) and Milgrom (1981).

${ }^{39}$ For example, children of self-informed parents may be less costly to educate if those parents are more likely to participate and volunteer in school activities and education.
} 


\section{REFERENCES}

Angrist, Joshua, Eric Bettinger, and Michael Kremer, "Long-Term Educational Consequences of Secondary School Vouchers: Evidence from Administrative Records in Colombia,” American Economic Review, 96 (2006), 847-862.

Armor, David J., and Brett M. Peiser, "Interdistrict Choice in Massachusetts,” in Learning from School Choice, Paul E. Peterson and Bryan C. Hassel, eds. (Washington, DC: Brookings Institution Press, 1998).

Ausubel, Lawrence M., “The Failure of Competition in the Credit Card Market,” American Economic Review, 81 (1991), 50-81.

Chetty, Raj, Adam Looney, and Kory Kroft, "Salience and Taxation: Theory and Evidence," NBER Working Paper No. 13330, 2007.

Choi, James, David Laibson, and Brigitte C. Madrian, "Why Does the Law of One Price Fail? An Experiment on Index Mutual Funds” NBER Working Paper No. 12261, 2006.

Cullen, Julie Berry, and Brian A. Jacob, "Is Gaining Access to Selective Elementary Schools Gaining Ground? Evidence from Randomized Lotteries?,” NBER Working Paper No. 13443, 2007.

Cullen, Julie Berry, Brian A. Jacob, and Steven Levitt, “The Effect of School Choice on Participants: Evidence from Randomized Lotteries,” Econometrica, 74 (2006), 19911230.

Fossey, Richard, “Open Enrollment in Massachusetts: Why Families Choose,” Educational Evaluation and Policy Analysis, 16 (1994), 320-334.

Grossman, Sanford J., “The Informational Role of Warranties and Private Disclosure about Product Quality,” Journal of Law and Economics, 24 (1981), 461-483.

Hastings, Justine S., Thomas J. Kane, and Douglas O. Staiger, "Parental Preferences and School Competition: Evidence from a Public School Choice Program,” NBER Working Paper No. 11805, 2006.

Hastings, Justine S., Thomas J. Kane, and Douglas O. Staiger, "Preferences and Heterogeneous Treatment Effects in a Public School Choice Lottery,” NBER Working Paper No. 12145, 2007.

Hastings, Justine S., and Jeffrey M. Weinstein, "No Child Left Behind: Estimating the Impact on Choices and Student Outcomes,” NBER Working Paper No. 13009, 2007.

Hastings, Justine S., and Jeffrey M. Weinstein, “Does Gender Influence Gains from Increased Academic Opportunity?” mimeo, Yale University, 2008. 
Hastings, Justine S., and Lydia Tejeda-Ashton, "Financial Literacy, Information, and Demand Elasticity: Survey and Experimental Evidence,” mimeo, Yale University, 2008.

Hastings, Justine S., Richard Van Weelden, and Jeffrey M. Weinstein, "Preferences, Information, and Parental Choice Behavior in Public School Choice,” NBER Working Paper No. 12995, 2007.

Hoxby, Caroline M., and Gretchen Weingarth-Salyer, “Taking Race Out of the Equation: School Reassignment and the Structure of Peer Effects,” mimeo, Stanford University, 2005.

Jacob, Brian A., and Lars Lefgren, "What Do Parents Value in Education? An Empirical Investigation of Parents’ Revealed Preferences for Teachers,” Quarterly Journal of Economics, 122 (2007), 1603-1637.

Kling, Jeffrey R., Sendhil Mullainathan, Eldar Shafir, Lee Vermeulen, and Marian V. Wrobel, “Confusion and Choice in Medicare Drug Plan Selection,” mimeo, Harvard University, 2008.

McFadden, Daniel, "Free Markets and Fettered Consumers (Presidential Address to the American Economic Association),” American Economic Review, 96 (2006), 5-29.

Milgrom, Paul R., “Good News and Bad News: Representation Theorems and Applications,” Bell Journal of Economics, 12 (1981), 380-391.

Rouse, Cecilia Elena, "Private School Vouchers and Student Achievement: An Evaluation of the Milwaukee Parental Choice Program,” Quarterly Journal of Economics, 113 (1998), 553602.

Schneider, Mark, and Jack Buckley, "What do Parents Want from Schools? Evidence from the Internet,” Educational Evaluation and Policy Analysis, 24 (2002), 133-144.

United States Department of Education, North Carolina Consolidated State Application Accountability Workbook. (Washington, DC: United States Department of Education, 2005). Available at www.ncpublicschools.org/docs/nclb/federal/consolidated/20050630workbook.pdf.

United States Department of Education, Public School Choice. (Washington, DC: United States Department of Education, 2004). Available at www.ed.gov/policy/elsec/guid/schoolchoiceguid.pdf.

Winter, Joachim, Rowilma Balza, Frank Caro, Florian Heiss, Byung-hill Jun, Rosa Matzkin, and Daniel McFadden, "Medicare Prescription Drug Coverage: Consumer Information and Preferences,” Proceedings of the National Academy of Sciences, 103 (2006), 7929-7934. 
Table I

Summary Statistics for Students in 2004 NCLB Natural Experiment and 2006 Field Experiment

\begin{tabular}{|c|c|c|c|c|c|}
\hline \multirow[b]{2}{*}{ Variable } & \multicolumn{2}{|c|}{ 2003-2004 school year } & \multicolumn{3}{|c|}{ 2005-2006 school year } \\
\hline & All students ${ }^{1}$ & $\begin{array}{c}\text { In NCLB } \\
\text { natural } \\
\text { experiment }\end{array}$ & $\begin{array}{c}\text { All } \\
\text { students }\end{array}$ & $\begin{array}{c}\text { Field } \\
\text { experiment: } \\
\text { Non-NCLB } \\
\text { panel }\end{array}$ & $\begin{array}{c}\text { Field } \\
\text { experiment: } \\
\text { NCLB panel }\end{array}$ \\
\hline & $(1)$ & $(2)$ & (3) & $(4)$ & $(5)$ \\
\hline African Amercian ${ }^{3}$ & $\begin{array}{c}0.428 \\
(0.495)\end{array}$ & $\begin{array}{c}0.840 \\
(0.366)\end{array}$ & $\begin{array}{c}0.429 \\
(0.495)\end{array}$ & $\begin{array}{c}0.570 \\
(0.495)\end{array}$ & $\begin{array}{c}0.665 \\
(0.472)\end{array}$ \\
\hline Lunch recipient ${ }^{4}$ & $\begin{array}{c}0.421 \\
(0.494)\end{array}$ & $\begin{array}{c}0.863 \\
(0.343)\end{array}$ & $\begin{array}{c}0.461 \\
(0.498)\end{array}$ & $\begin{array}{c}0.608 \\
(0.488)\end{array}$ & $\begin{array}{c}0.837 \\
(0.369)\end{array}$ \\
\hline Student's combined test score ${ }^{5}$ & $\begin{array}{c}0.003 \\
(0.946)\end{array}$ & $\begin{array}{l}-0.568 \\
(0.772)\end{array}$ & $\begin{array}{c}0.006 \\
(0.948)\end{array}$ & $\begin{array}{l}-0.339 \\
(0.850)\end{array}$ & $\begin{array}{l}-0.518 \\
(0.827)\end{array}$ \\
\hline Income $^{6}$ & $\begin{array}{c}56,271 \\
(27,346)\end{array}$ & $\begin{array}{c}32,058 \\
(13,253)\end{array}$ & $\begin{array}{c}56,764 \\
(26,915)\end{array}$ & $\begin{array}{c}48,767 \\
(21,278)\end{array}$ & $\begin{array}{c}35,194 \\
(14,943)\end{array}$ \\
\hline Number of unexcused absences ${ }^{7}$ & $\begin{array}{c}3.933 \\
(7.070)\end{array}$ & $\begin{array}{c}5.663 \\
(6.717)\end{array}$ & $\begin{array}{c}4.116 \\
(7.152)\end{array}$ & $\begin{array}{c}3.449 \\
(6.004)\end{array}$ & $\begin{array}{c}4.387 \\
(6.002)\end{array}$ \\
\hline Number of suspensions ${ }^{8}$ & $\begin{array}{c}1.180 \\
(4.440)\end{array}$ & $\begin{array}{c}2.281 \\
(6.485)\end{array}$ & $\begin{array}{c}1.126 \\
(4.489)\end{array}$ & $\begin{array}{c}1.500 \\
(5.550)\end{array}$ & $\begin{array}{c}1.809 \\
(5.882)\end{array}$ \\
\hline Number of students & 115,716 & 6,695 & 125,313 & 6,328 & 10,134 \\
\hline
\end{tabular}

Notes: Standard deviations are in parentheses. ${ }^{1}$ In columns (1) and (3), we exclude 2,071 and 141 students, respectively, with missing address data. ${ }^{2}$ There were 8,284 students who received NCLB-mandated information in 2004. We began with the 8,284 students who received NCLB-mandated information. We exclude inactive students (221), special needs students and retentions $(1,245)$, and students with missing demographics $(123)$. ${ }^{3}$ Indicates whether student's race is coded as African American in the administrative dataset. ${ }^{4}$ Indicates whether student received free- or reducedlunch subsidies according to administrative data. ${ }^{5}$ Average of test score in reading and math for North Carolina End of Grade exams, standardized by the district-wide mean and standard deviation for each grade level. Since only students in grades three through eight take exams, samples sizes are 50,182; 4,646; 62,759; 3,920; and 6,117, respectively, in columns (1) through (5). ${ }^{6}$ Based on student residential locations, we computed each student's income as the median income in the 2000 Census for people of a student's own race living in a student's block group. ${ }^{7}$ Computed from end of year tabulations of absences in the administrative database. Sample sizes for absences and suspensions are 115,699; 6,695; 125,285; 6,322; and 10,132, respectively, in columns (1) through (5), since not all students remain through the end of the year. ${ }^{8}$ Computed from end of year tabulations of in-school and out-of-school suspensions in the administrative database. 
Table II

Effect of 2004 NCLB-Mandated Information on Parental Choice Behavior

\begin{tabular}{|c|c|c|c|}
\hline Variable & $\begin{array}{l}\text { Spring } 2004 \\
\text { choice round }^{1}\end{array}$ & $\begin{array}{c}\text { July } 2004 \text { NCLB } \\
\text { choice round }^{1}\end{array}$ & $\begin{array}{c}\text { Difference: } \\
\text { July - Spring }\end{array}$ \\
\hline & $(1)$ & $(2)$ & $(3)$ \\
\hline \multicolumn{4}{|l|}{ All parents of NCLB students ${ }^{3}$} \\
\hline Fraction choosing school and program other than & 0.112 & 0.163 & $0.051 * * *$ \\
\hline NCLB school and program first & $(0.315)$ & $(0.369)$ & $(0.006)$ \\
\hline Test score of first-choice school and program & 0.053 & 0.100 & $0.047 * * *$ \\
\hline minus test score of NCLB school and program ${ }^{4}$ & $(0.207)$ & $(0.267)$ & $(0.004)$ \\
\hline Number of students & 6,695 & 6,695 & 6,695 \\
\hline \multicolumn{4}{|c|}{ Parents who chose NCLB school and program first in Spring 2004 choice round ${ }^{5}$} \\
\hline Fraction choosing school and program other than & 0 & 0.145 & $0.145 * * *$ \\
\hline NCLB school and program first & -- & $(0.353)$ & $(0.005)$ \\
\hline Test score of first-choice school and program & 0 & 0.088 & $0.088 * * *$ \\
\hline minus test score of NCLB school and program & -- & $(0.251)$ & $(0.003)$ \\
\hline Number of students & 5,946 & 5,946 & 5,946 \\
\hline
\end{tabular}

Notes: ${ }^{1}$ Standard deviations are in parentheses. ${ }^{2}$ Standard errors from a t-test of the equality of Spring 2004 and July 2004 means are in parentheses. Asterisks indicate significance $\left(*=.10,{ }^{* *}=.05, * * *=.01\right) .{ }^{3}$ We began with the 8,284 students who received NCLB-mandated information. We exclude inactive students (221), special needs students and retentions $(1,245)$, and students with missing demographics (123). ${ }^{4}$ School and program test scores are school and program means of student-level average test scores in reading and math for the North Carolina End of Grade exams, standardized by the district-wide mean and standard deviation for each grade level. ${ }^{5}$ Sample excludes parents who did not choose their NCLB school and program first in Spring 2004. 
Differences in Choice Characteristics Between Spring 2004 Choice Round and July 2004 NCLB Choice Round

\begin{tabular}{|c|c|c|c|}
\hline Variable & $\begin{array}{c}\text { All } \\
\text { students }^{1}\end{array}$ & $\begin{array}{c}\text { African } \\
\text { American }^{2}\end{array}$ & $\begin{array}{c}\text { Not African } \\
\text { American }\end{array}$ \\
\hline & $(1)$ & $(2)$ & (3) \\
\hline \multicolumn{4}{|c|}{ Test score at first-choice school and program ${ }^{3}$} \\
\hline Spring 2004 choice round & -0.502 & -0.513 & -0.421 \\
\hline July 2004 NCLB choice round & -0.017 & -0.034 & 0.108 \\
\hline \multicolumn{4}{|c|}{ Average test score of schools and programs within five miles ${ }^{4}$} \\
\hline Spring 2004 choice round & -0.322 & -0.328 & -0.277 \\
\hline July 2004 NCLB choice round & -0.247 & -0.253 & -0.206 \\
\hline Number of students & 1,092 & 963 & 129 \\
\hline
\end{tabular}

Notes: ${ }^{1}$ This sub-sample includes students whose parents' first choice in July 2004 was a school and program other than their NCLB school and program. ${ }^{2}$ Sub-sample of students whose race is coded as African American in the administrative dataset. ${ }^{3}$ School and program test scores are school and program means of student-level average test scores in reading and math for the North Carolina End of Grade exams, standardized by the district-wide mean and standard deviation for each grade level. ${ }^{4}$ We computed the driving distance (in miles) from each student's residence to each school that the student could choose. This variable is the average test score defined in footnote 4 for all schools within five miles. For the five students in the spring and the fifteen students in July with no schools within five miles, we used the average test score of schools and programs within ten miles. 


\section{Table IV}

Characteristics that Influenced Response to NCLB-Mandated Information

\begin{tabular}{|c|c|c|c|c|}
\hline \multirow[t]{2}{*}{ Variable } & \multicolumn{2}{|c|}{$\begin{array}{c}\text { Dependent variable: } \\
\text { Chose non-NCLB school and } \\
\text { program first in July } 2004\end{array}$} & \multicolumn{2}{|c|}{$\begin{array}{c}\text { Dependent variable: } \\
\text { Average test score at first-choice school } \\
\text { and program in July } 2004^{1}\end{array}$} \\
\hline & $(1)^{2}$ & $(2)^{3}$ & $(3)^{4}$ & $(4)^{5}$ \\
\hline Choice set characteristics & & & & \\
\hline Distance to NCLB school $^{6}$ & $\begin{array}{c}0.003 \\
(0.003)\end{array}$ & $\begin{array}{c}0.004 \\
(0.003)\end{array}$ & $\begin{array}{c}-0.015 * * * \\
(0.004)\end{array}$ & $\begin{array}{c}-0.016 * * * \\
(0.004)\end{array}$ \\
\hline Average distance to schools within five miles ${ }^{7}$ & $\begin{array}{c}0.002 \\
(0.007)\end{array}$ & $\begin{array}{l}-0.007 \\
(0.008)\end{array}$ & $\begin{array}{l}-0.011 \\
(0.016)\end{array}$ & $\begin{array}{c}-0.004 \\
(0.017)\end{array}$ \\
\hline Average test score of schools within five miles ${ }^{8}$ & $\begin{array}{c}0.091^{* * *} \\
(0.033)\end{array}$ & $\begin{array}{c}0.110^{* *} \\
(0.041)\end{array}$ & $\begin{array}{c}0.233^{* * *} \\
(0.057)\end{array}$ & $\begin{array}{c}0.186^{* * *} \\
(0.062)\end{array}$ \\
\hline \multicolumn{5}{|l|}{ Student characteristics } \\
\hline Single child in $\mathrm{CMS}^{9}$ & $\begin{array}{c}0.032 * * * \\
(0.011)\end{array}$ & $\begin{array}{c}0.024^{* *} \\
(0.011)\end{array}$ & $\begin{array}{c}-0.006 \\
(0.020)\end{array}$ & $\begin{array}{c}-0.002 \\
(0.023)\end{array}$ \\
\hline Rising grader $^{10}$ & $\begin{array}{c}0.033^{* * *} \\
(0.010)\end{array}$ & $\begin{array}{c}0.035^{* * *} \\
(0.013)\end{array}$ & $\begin{array}{c}-0.052 * \\
(0.028)\end{array}$ & $\begin{array}{c}-0.039 \\
(0.030)\end{array}$ \\
\hline African American ${ }^{11}$ & $\begin{array}{c}0.051 * * * \\
(0.017)\end{array}$ & $\begin{array}{c}0.062^{* * *} \\
(0.016)\end{array}$ & $\begin{array}{c}-0.079 * * * \\
(0.028)\end{array}$ & $\begin{array}{c}-0.081^{* *} \\
(0.036)\end{array}$ \\
\hline Lunch recipient ${ }^{12}$ & $\begin{array}{c}0.022 \\
(0.016)\end{array}$ & $\begin{array}{c}0.029 * * \\
(0.014)\end{array}$ & $\begin{array}{c}-0.070 * * \\
(0.032)\end{array}$ & $\begin{array}{c}-0.082 * * \\
(0.037)\end{array}$ \\
\hline Female $^{13}$ & $\begin{array}{l}-0.004 \\
(0.011)\end{array}$ & $\begin{array}{l}-0.007 \\
(0.011)\end{array}$ & $\begin{array}{l}-0.027 \\
(0.024)\end{array}$ & $\begin{array}{l}-0.025 \\
(0.024)\end{array}$ \\
\hline Demeaned income $^{14}$ & $\begin{array}{l}-0.0002 \\
(0.0004)\end{array}$ & $\begin{array}{l}-0.0001 \\
(0.0004)\end{array}$ & $\begin{array}{l}-0.001 \\
(0.001)\end{array}$ & $\begin{array}{c}-0.001 \\
(0.001)\end{array}$ \\
\hline Baseline number of unexcused absences ${ }^{15}$ & $\begin{array}{c}-0.002^{* * * *} \\
(0.001)\end{array}$ & $\begin{array}{c}-0.002 * * * \\
(0.001)\end{array}$ & $\begin{array}{c}-0.003 \\
(0.002)\end{array}$ & $\begin{array}{c}-0.004^{*} \\
(0.002)\end{array}$ \\
\hline Baseline number of suspensions ${ }^{16}$ & $\begin{array}{c}0.002 * * \\
(0.001)\end{array}$ & $\begin{array}{c}0.003^{* * *} \\
(0.001)\end{array}$ & $\begin{array}{c}0.001 \\
(0.001)\end{array}$ & $\begin{array}{c}0.002 \\
(0.002)\end{array}$ \\
\hline Baseline test score $^{17}$ & $\begin{array}{c}0.016 * * \\
(0.008)\end{array}$ & $\begin{array}{l}0.014^{*} \\
(0.008)\end{array}$ & $\begin{array}{c}0.025 \\
(0.015)\end{array}$ & $\begin{array}{l}0.032 * \\
(0.018)\end{array}$ \\
\hline Chose non-NCLB school and program first in spring & $\begin{array}{c}0.133^{* * *} \\
(0.024)\end{array}$ & $\begin{array}{l}-- \\
--\end{array}$ & $\begin{array}{c}0.104^{* * *} \\
(0.023)\end{array}$ & $\begin{array}{l}-- \\
--\end{array}$ \\
\hline Constant & $\begin{array}{c}0.092 * * \\
(0.038)\end{array}$ & $\begin{array}{c}0.108 * * \\
(0.043)\end{array}$ & $\begin{array}{c}0.316^{* * *} \\
(0.068)\end{array}$ & $\begin{array}{c}0.300 * * * \\
(0.073)\end{array}$ \\
\hline Mean of dependent variable & 0.176 & 0.155 & 0.618 & 0.608 \\
\hline Number of students & 4,646 & 4,022 & 818 & 623 \\
\hline Adjusted R-squared & 0.04 & 0.03 & 0.14 & 0.14 \\
\hline
\end{tabular}

Notes: OLS estimation with NCLB school-program fixed effects. Standard errors adjust for clustering at the level of the NCLB school-program and grade level. Asterisks indicate significance $(*=.10, * *=.05, * * *=.01) .{ }^{1}$ School and program test scores are school and program means of student-level average test scores in reading and math for the North Carolina End of Grade exams, standardized by the district-wide mean and standard deviation for each grade level. ${ }^{2}$ Sample includes students in grades three through eight who took the North Carolina End of Grade exam. ${ }^{3}$ Sample includes all students in column (1) who did not choose NCLB school and program first in the spring. ${ }^{4}$ Sample includes all students in column (1) who did not choose NCLB school and program first in July. ${ }^{5}$ Sample includes all students in column (2) who did not choose NCLB school and program first in either choice round. ${ }^{6}$ Driving distance (in miles) from each student's residence to her NCLB school. ${ }^{7}$ We computed the driving distance (in miles) from each student's residence to each school that the student could choose. We then calculated the mean distance for all schools and programs within five miles of the student's residence. For the 76, 67, 15, and 11 students in columns (1) through (4), respectively, with no schools within five miles, we used the driving distance to the closest school. ${ }^{8}$ We computed the driving distance (in miles) from each student's residence to each school that the student could choose. We then calculated the mean test score for all schools and programs within five miles of the student's residence (see footnote 1). For the 76, 67, 15, and 11 students in columns (1) through (4), respectively, with no schools within five miles, we used the average test score of schools and programs within ten miles. ${ }^{9}$ Indicates whether student does not have a sibling in CMS. ${ }^{10}$ Indicates whether student is entering kindergarten or sixth grade in the fall. ${ }^{11}$ Indicates whether student's race is coded as African American in the administrative dataset. ${ }^{12}$ Indicates whether student received free- or reduced-lunch subsidies according to administrative data. ${ }^{13}$ Indicates whether student is female according to administrative data. ${ }^{14}$ Based on student residential locations, we computed each student's income as the median income in the 2000 Census for people of a student's own race living in a student's block group. Demeaned income is obtained by subtracting the countywide average income of $\$ 51,000$ and dividing by $1,000 .{ }^{15}$ Computed from end of year tabulations of absences in the administrative database. ${ }^{16}$ Computed from end of year tabulations of in-school and out-of-school suspensions in the administrative database. ${ }^{17}$ Average of the test score in reading and math for the North Carolina End of Grade exams, standardized by the district-wide mean and standard deviation for each grade level. 


\section{Table V}

Averaged Baseline Characteristics: Treatment and Control Groups, 2006 Field Experiment

\begin{tabular}{|c|c|c|c|c|c|}
\hline \multirow[t]{2}{*}{ School-zone averaged variable } & \multicolumn{3}{|c|}{$\begin{array}{c}\text { Sample means and standard } \\
\text { deviations }\end{array}$} & \multicolumn{2}{|c|}{$\begin{array}{l}\text { Regression-adjusted } \\
\text { mean differences }^{1}\end{array}$} \\
\hline & $\begin{array}{c}\text { Received } \\
\text { score } \\
\text { form }\end{array}$ & $\begin{array}{c}\text { Received } \\
\text { odds } \\
\text { form }\end{array}$ & $\begin{array}{l}\text { Control } \\
\text { group }\end{array}$ & $\begin{array}{c}\text { Received } \\
\text { score } \\
\text { form }\end{array}$ & $\begin{array}{c}\text { Received } \\
\text { odds } \\
\text { form }\end{array}$ \\
\hline Fraction African American students ${ }^{2}$ & $\begin{array}{c}0.641 \\
(0.162)\end{array}$ & $\begin{array}{c}0.548 \\
(0.186)\end{array}$ & $\begin{array}{c}0.620 \\
(0.215)\end{array}$ & $\begin{array}{l}0.0006 \\
(0.042) \\
{[0.989]}\end{array}$ & $\begin{array}{c}-0.044 \\
(0.064) \\
{[0.494]}\end{array}$ \\
\hline Fraction lunch recipients ${ }^{3}$ & $\begin{array}{c}0.763 \\
(0.128)\end{array}$ & $\begin{array}{c}0.748 \\
(0.144)\end{array}$ & $\begin{array}{c}0.716 \\
(0.229)\end{array}$ & $\begin{array}{c}0.046 \\
(0.038) \\
{[0.237]}\end{array}$ & $\begin{array}{c}0.029 \\
(0.059) \\
{[0.625]}\end{array}$ \\
\hline Average income ${ }^{4}$ & $\begin{array}{l}41725 \\
(8996)\end{array}$ & $\begin{array}{l}41573 \\
(8456)\end{array}$ & $\begin{array}{c}43334 \\
(13598)\end{array}$ & $\begin{array}{c}-1811 \\
(2289) \\
{[0.432]}\end{array}$ & $\begin{array}{l}-2417 \\
(3504) \\
{[0.493]}\end{array}$ \\
\hline Average test score ${ }^{5}$ & $\begin{array}{l}-0.404 \\
(0.248)\end{array}$ & $\begin{array}{l}-0.452 \\
(0.191)\end{array}$ & $\begin{array}{l}-0.426 \\
(0.281)\end{array}$ & $\begin{array}{c}0.019 \\
(0.059) \\
{[0.751]}\end{array}$ & $\begin{array}{c}-0.123 \\
(0.081) \\
{[0.136]}\end{array}$ \\
\hline Average number of unexcused absences ${ }^{6}$ & $\begin{array}{l}3.932 \\
(1.994)\end{array}$ & $\begin{array}{c}4.139 \\
(2.192)\end{array}$ & $\begin{array}{c}4.220 \\
(2.673)\end{array}$ & $\begin{array}{c}-0.515 \\
(0.460) \\
{[0.267]}\end{array}$ & $\begin{array}{c}0.406 \\
(0.704) \\
{[0.566]}\end{array}$ \\
\hline Average number of suspensions ${ }^{7}$ & $\begin{array}{c}1.922 \\
(2.652)\end{array}$ & $\begin{array}{l}1.569 \\
(2.483)\end{array}$ & $\begin{array}{c}1.912 \\
(2.602)\end{array}$ & $\begin{array}{c}-0.100 \\
(0.530) \\
{[0.850]}\end{array}$ & $\begin{array}{c}-0.624 \\
(0.811) \\
{[0.444]}\end{array}$ \\
\hline Number of school-zones & 33 & 11 & 33 & 77 & 77 \\
\hline
\end{tabular}

Notes: ${ }^{1}$ All regressions include randomization-block fixed effects. Standard errors are in parentheses, and p-values are in brackets. Asterisks indicate significance $(*=.10, * *=.05, * * *=.01) .{ }^{2}$ School-zone fraction of students whose race is coded as African American in the administrative dataset. ${ }^{3}$ School-zone fraction of students received free- or reduced-lunch subsidies according to administrative data. ${ }^{4}$ Based on student residential locations, we computed each student's income as the median income in the 2000 Census for people of a student's own race living in a student's block group. ${ }^{5}$ School-zone average of the student mean test score in reading and math for the North Carolina End of Grade exams standardized by the district-wide mean and standard deviation for each grade level. Since only students in grades three through eight take North Carolina End of Grade exams, the samples sizes for this variable are 28 school-zones that received Score forms, 11 school-zones that received Odds forms, and 25 school-zones that were in the control group. ${ }^{6}$ School-zone average of student end of year tabulations of absences in the administrative database. ${ }^{7}$ School-zone average of student's number of out-of-school suspensions in the administrative database. 


\section{Table VI}

Impact of Receiving Information on Aggregate Parental Choice in 2006 Field Experiment

\begin{tabular}{|c|c|c|c|c|}
\hline \multirow{2}{*}{ Dependent variable: } & \multicolumn{2}{|c|}{ Ordinary Least Squares $^{1}$} & \multicolumn{2}{|c|}{ Weighted Least Squares ${ }^{2}$} \\
\hline & $\begin{array}{l}\text { Fraction } \\
\text { choosing non- } \\
\text { guaranteed } \\
\text { option first }^{3}\end{array}$ & $\begin{array}{l}\text { Average difference in } \\
\text { test score between first- } \\
\text { choice and guaranteed } \\
\text { option }^{4}\end{array}$ & $\begin{array}{l}\text { Fraction } \\
\text { choosing non- } \\
\text { guaranteed } \\
\text { option first }\end{array}$ & $\begin{array}{l}\text { Average difference in } \\
\text { test score between } \\
\text { first-choice and } \\
\text { guaranteed option }\end{array}$ \\
\hline \multicolumn{5}{|l|}{ Panel 1: Sample includes all school-zones } \\
\hline \multicolumn{5}{|l|}{ Regression with scores and odds separately } \\
\hline \multirow[t]{2}{*}{ Scores } & 0.026 & 0.039 & 0.007 & 0.013 \\
\hline & $(0.028)$ & $(0.026)$ & $(0.026)$ & $(0.025)$ \\
\hline \multirow[t]{2}{*}{ Odds } & 0.008 & 0.055 & 0.0003 & 0.023 \\
\hline & $(0.043)$ & $(0.040)$ & $(0.039)$ & $(0.037)$ \\
\hline \multicolumn{5}{|l|}{ Regression with scores and odds pooled } \\
\hline \multirow[t]{2}{*}{ Received information } & 0.021 & 0.043 & 0.006 & 0.016 \\
\hline & $(0.026)$ & $(0.024)$ & $(0.024)$ & $(0.023)$ \\
\hline Mean of dependent variable & 0.258 & 0.136 & 0.237 & 0.142 \\
\hline Number of school-zones & 77 & 77 & 77 & 77 \\
\hline \multirow{2}{*}{\multicolumn{5}{|c|}{$\begin{array}{l}\text { Panel 2: Sample includes non-NCLB school-zones only } \\
\quad \text { Regression with scores and odds separately }\end{array}$}} \\
\hline & & & & \\
\hline \multirow[t]{2}{*}{ Scores } & $0.066 *$ & $0.097 * * *$ & $0.073 *$ & $0.101 * * *$ \\
\hline & $(0.036)$ & $(0.029)$ & $(0.036)$ & $(0.027)$ \\
\hline \multirow[t]{2}{*}{ Odds } & 0.045 & $0.107 * *$ & 0.079 & $0.104^{* *}$ \\
\hline & $(0.057)$ & $(0.046)$ & $(0.060)$ & $(0.043)$ \\
\hline \multicolumn{5}{|l|}{ Regression with scores and odds pooled } \\
\hline \multirow{2}{*}{ Received information } & $0.061 *$ & $0.100 * * *$ & $0.075 * *$ & $0.101^{* * *}$ \\
\hline & $(0.032)$ & $(0.026)$ & $(0.032)$ & $(0.023)$ \\
\hline Mean of dependent variable & 0.319 & 0.142 & 0.305 & 0.136 \\
\hline Number of school-zones & 46 & 46 & 46 & 46 \\
\hline \multicolumn{5}{|c|}{ Panel 3: Sample includes NCLB school-zones only } \\
\hline \multicolumn{5}{|l|}{ Regression with scores and odds separately } \\
\hline \multirow[t]{2}{*}{ Scores } & -0.027 & -0.037 & -0.026 & -0.030 \\
\hline & $(0.044)$ & $(0.042)$ & $(0.037)$ & $(0.038)$ \\
\hline \multirow[t]{2}{*}{ Odds } & -0.044 & -0.020 & -0.039 & -0.020 \\
\hline & $(0.065)$ & $(0.062)$ & $(0.054)$ & $(0.055)$ \\
\hline \multicolumn{5}{|l|}{ Regression with scores and odds pooled } \\
\hline \multirow[t]{2}{*}{ Received information } & -0.031 & -0.033 & -0.029 & -0.027 \\
\hline & $(0.041)$ & $(0.039)$ & $(0.035)$ & $(0.035)$ \\
\hline Mean of dependent variable & 0.168 & 0.128 & 0.195 & 0.146 \\
\hline Number of school-zones & 31 & 31 & 31 & 31 \\
\hline
\end{tabular}

Notes: All regressions include randomization-block fixed effects. Standard errors are in parentheses. Asterisks indicate significance $(*=.10, * *=.05$, $* * *=.01) .{ }^{1}$ Each column presents separate OLS regressions of aggregated choice behavior on indicators for whether the school-zone received a Score form or an Odds form (Scores and Odds Separately) or an indicator for whether the school-zone received any type of information (Scores and Odds pooled), controlling for randomization-block fixed effects. ${ }^{2}$ Weight by the number of students in each school-zone. ${ }^{3} \mathrm{~A}$ guaranteed option is the school and program in which the student was currently enrolled, or, in the case of rising-grade students, her home school. ${ }^{4}$ School and program test scores computed by taking school and program means of student-level average test scores in reading and math for the North Carolina End of Grade exams, standardized by the district-wide mean and standard deviation for each grade level. For high school choices, we used the results of the English I End of Course exam, taken by most ninth grade students. 


\section{Table VII}

\section{Impact of Information on Student-Level Choice Behavior:}

Non-NCLB Sample in 2006 Field Experiment

\begin{tabular}{|c|c|c|}
\hline \multirow[t]{2}{*}{$\begin{array}{l}\text { Dependent variable: } \\
\text { Difference between test score at first-choice option and guaranteed option }{ }^{1}\end{array}$} & $\begin{array}{c}\text { All } \\
\text { students }\end{array}$ & $\begin{array}{l}\text { Sub-sample choosing non- } \\
\text { guaranteed option first }\end{array}$ \\
\hline & (1) & $(2)$ \\
\hline \multicolumn{3}{|l|}{ Main effect } \\
\hline \multirow[t]{2}{*}{ Received information ${ }^{2}$} & 0.017 & 0.189 \\
\hline & $(0.047)$ & $(0.141)$ \\
\hline \multicolumn{3}{|l|}{ Interactions with choice-set characteristics } \\
\hline \multirow[t]{2}{*}{ Information * Distance to guaranteed option ${ }^{3}$} & $-0.015 *$ & $-0.045^{* * *}$ \\
\hline & $(0.008)$ & $(0.015)$ \\
\hline \multirow[t]{2}{*}{ Information * Average distance to schools within five miles ${ }^{4}$} & 0.015 & 0.026 \\
\hline & $(0.010)$ & $(0.018)$ \\
\hline \multirow[t]{2}{*}{ Information * Average test score of schools within five miles ${ }^{5}$} & $0.109^{*}$ & $0.243^{*}$ \\
\hline & $(0.060)$ & $(0.122)$ \\
\hline \multirow[t]{2}{*}{ Information * Test score at guaranteed option } & 0.030 & -0.052 \\
\hline & $(0.070)$ & $(0.126)$ \\
\hline \multicolumn{3}{|l|}{ Interactions with demographics } \\
\hline \multirow[t]{2}{*}{ Information * Single child in $\mathrm{CMS}^{6}$} & $0.026 *$ & 0.014 \\
\hline & $(0.016)$ & $(0.038)$ \\
\hline \multirow[t]{2}{*}{ Information * African American } & $0.060^{* *}$ & 0.018 \\
\hline & $(0.022)$ & $(0.075)$ \\
\hline \multirow[t]{2}{*}{ Information * Lunch recipient } & 0.035 & 0.040 \\
\hline & $(0.038)$ & $(0.071)$ \\
\hline \multicolumn{3}{|l|}{ Interactions with baseline academic performance } \\
\hline \multirow[t]{2}{*}{ Information $*$ Test score ${ }^{7}$} & 0.014 & 0.011 \\
\hline & $(0.022)$ & $(0.029)$ \\
\hline \multirow[t]{2}{*}{ Information $*$ Number of absences $^{8}$} & -0.002 & -0.001 \\
\hline & $(0.002)$ & $(0.006)$ \\
\hline \multirow[t]{2}{*}{ Information $^{*}$ Number of suspensions ${ }^{9}$} & -0.001 & 0.003 \\
\hline & $(0.002)$ & $(0.004)$ \\
\hline Number of students & 3,920 & 1,222 \\
\hline Adjusted R-squared & 0.17 & 0.33 \\
\hline Joint P-value for information and interactions & 0.0000 & 0.0000 \\
\hline \multicolumn{3}{|c|}{ 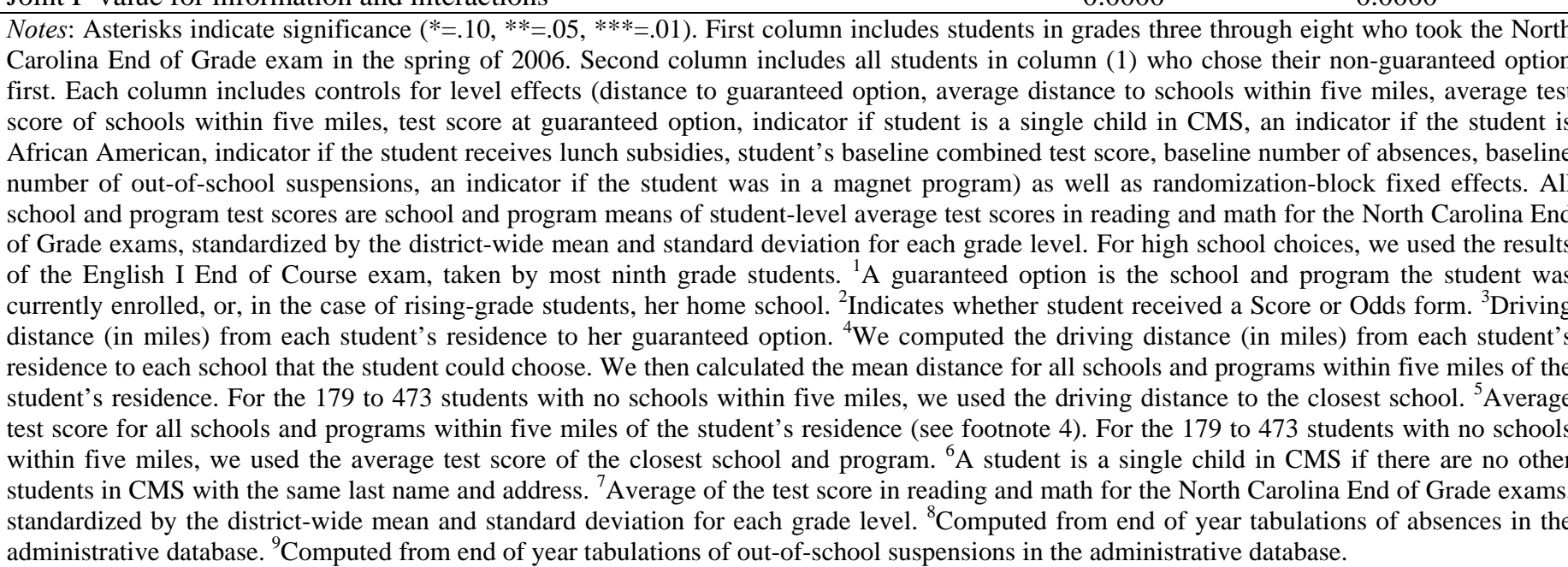 } \\
\hline
\end{tabular}




\section{Table VIII}

\section{Limited Information Maximum Likelihood Estimates of Effect of Test Score at School Attended on Own Test Score: Non-NCLB Students in 2006 Field Experiment}

Dependent variable:

Mean of reading and math test score in 2007

Test score of attended school and

program

Model 1

0.336

(0.550)

$$
33
$$

0.62

(a) Received information
Model 2

0.183

(0.398)

3,280

0.70

(a) Received information
Model 3

0.355

(0.232)

3,280

0.69

(a) Received information

(b) Info * Single child

(c) Info * Average test score of schools within five miles
Model 4

$0.409 * *$

(a) Received information

(b) Info * Single child

(c) Info * Average test score of schools within five miles (d) Info * Average distance to schools within five miles (e) Info * Distance to guaranteed school

Joint P-value for excluded instruments

0.092

0.100

0.038

0.007

Notes: Asterisks indicate significance $(*=.10, * *=.05, * * *=.01)$. Column 1 presents LIML results for school-zone averaged test score of school attended on school-zoned averaged test score outcomes. There were 33 non-NCLB school-zones in the experiment where students were old enough to take standardized exams. The instrument for school-averaged score of school attended is an indicator if the school zone received Scores or Odds forms. Regression controls for randomization-block fixed-effects. Columns 2-4 present LIML results using student-level data. Coefficient reported is the impact of the test score at the attended school and program on own combined test score. Each regression controls for randomization block fixed effects and the following baseline covariates: indicator if the student is a single child in CMS, average test score of schools within five miles, average distance to schools within five miles, driving distance from each student's residence to her guaranteed option, an indicator if the student is African American, an indicator if the student receives lunch subsidies, average of the standardized test score in reading and math for the North Carolina End of Grade exams, number of absences, number of out-of-school suspensions, and an indicator for whether the student had at least one out-of-school suspension. The instruments for test score of the school attended are listed in each column. School and program test scores computed by taking school and program means of student-level average test scores in reading and math for the North Carolina End of Grade exams, standardized by the district-wide mean and standard deviation for each grade level. For high school choices, we used the results of the English I End of Course exam, taken by most ninth grade students. Own test score is average of the standardized test score in reading and math for the North Carolina End of Grade exams taken in Spring 2007, or for ninth grade students, standardized test score on English I End of Course exam. Standard errors are in parentheses and are clustered at the attended school-program and grade level in the 2006-2007 school year. 
Table IX

Characteristics of 2004 NCLB Lottery Winners and Lottery Losers

\begin{tabular}{|c|c|}
\hline Variable & Coefficient on won lottery \\
\hline $\begin{array}{l}\text { Baseline characteristic } \\
\text { African American }\end{array}$ & $\begin{array}{c}0.057 \\
(0.052)\end{array}$ \\
\hline Lunch recipient $^{2}$ & $\begin{array}{l}-0.018 \\
(0.013)\end{array}$ \\
\hline Female $^{3}$ & $\begin{array}{l}-0.001 \\
(0.068)\end{array}$ \\
\hline Income $^{4}$ & $\begin{array}{c}2,024 \\
(1,793)\end{array}$ \\
\hline Number of unexcused absences ${ }^{5}$ & $\begin{array}{l}-1.787 \\
(1.207)\end{array}$ \\
\hline Number of suspensions ${ }^{6}$ & $\begin{array}{c}0.704 \\
(1.044)\end{array}$ \\
\hline Test score ${ }^{7}$ & $\begin{array}{l}-0.051 \\
(0.056)\end{array}$ \\
\hline $\begin{array}{l}\text { School characteristics } \\
\text { Attended chosen school }^{8}\end{array}$ & $\begin{array}{c}0.602 * * * \\
(0.075)\end{array}$ \\
\hline Test score of attended school and program ${ }^{9}$ & $\begin{array}{l}0.336^{* * *} \\
(0.068)\end{array}$ \\
\hline Number of students & 223 \\
\hline
\end{tabular}

Notes: Asterisks indicate significance $(*=.10, * *=.05, * * *=.01)$. We restrict our sample to only students for whom lottery number alone determined admission. Of the 1,092 students who submitted a choice form in July 2004, 227 students fall into such priority groups. Four students left CMS before Fall 2004. Each row reports the coefficient on an indicator for whether the student won the lottery from separate regressions with dependent variable given by the row title. Each regression controls for lottery fixed effects. Standard errors adjust for clustering at the level of the 2004-2005 school year attended school-program and grade. ${ }^{1}$ Indicates whether student's race is coded as African American in the administrative dataset. ${ }^{2}$ Indicates whether student received free- or reduced-lunch subsidies according to administrative data. ${ }^{3}$ Indicates whether student is female according to administrative data. ${ }^{4}$ Based on student residential locations, we computed each student's income as the median income in the 2000 Census for people of a student's own race living in a student's block group. ${ }^{5}$ Computed from end of year tabulations of absences in the administrative database. ${ }^{6}$ Computed from end of year tabulations of in-school and out-of-school suspensions in the administrative database. ${ }^{7}$ Average of the test score in reading and math for the North Carolina End of Grade exams, standardized by the district-wide mean and standard deviation for each grade level. Because only students in grades three through eight take End of Grade exams, the sample size for this regression is $178 .{ }^{8}$ Indicates whether student attended her chosen school in $2004-2005$ school year. ${ }^{9}$ School and program test scores computed by taking school and program means of student-level average test scores in reading and math for the North Carolina End of Grade exams, standardized by the district-wide mean and standard deviation for each grade level. 
Table X

Instrumental Variables Estimates of Effect of Test Score of School Attended on Own Test Score for Students in 2004 NCLB Lottery

Dependent variable: Mean of reading and math test score in 2005

Test score of attended school and program Model 1 Model 2

0.172

$0.372^{*}$

(0.299)

Number of observations

161

161

R-squared

0.69

0.67

Excluded instruments for test score of attended school and program:

(a) Won lottery

(a) Won lottery

(b) Won lottery * (Test score at chosen school and program - Test score at NCLB school and program)

Joint P-Value for Excluded Instruments

0.0016

0.0019

Notes: Asterisks indicate significance $(*=.10, * *=.05, * * *=.01)$. We restrict our sample to only students for whom lottery number alone determined admission. Of the 1,092 students who submitted a choice form in July 2004, 227 students fall into such priority groups. Four students left CMS before Fall 2004. Of the 227 students, 161 took North Carolina End of Grade exams in math and reading in both Spring 2004 and Spring 2005 (only students in grades three through eight take exams in each year). School and program test scores computed by taking school and program means of student-level average test scores in reading and math for the North Carolina End of Grade exams, standardized by the districtwide mean and standard deviation for each grade level. Own test score is average of the standardized test score in reading and math for the North Carolina End of Grade exams taken in spring 2005. Each column reports the coefficient from an instrumental variables regression of own outcome test score on the test score of the attended school and program, controlling for lottery-block (grade and choice; see footnote 1) fixed effects and the following baseline covariates: an indicator if the student is African American, an indicator if the student receives lunch subsidies, an indicator for female, average of the student's baseline standardized test score in reading and math for the North Carolina End of Grade exams, number of absences, an indicator for five or more absences, number of in-school and out-of-school suspensions, and an indicator if the student had at least one suspension, income (based on student residential locations, we computed each student's income as the median income in the 2000 Census for people of a student's own race living in a student's block group), and the difference in test score between the chosen school and program and the NCLB school and program. The excluded instrument(s) for the test score of the attended school and program are listed in each column. Standard errors are in parentheses and are clustered at the attended school-program and grade level in the 2004-2005 school year. 


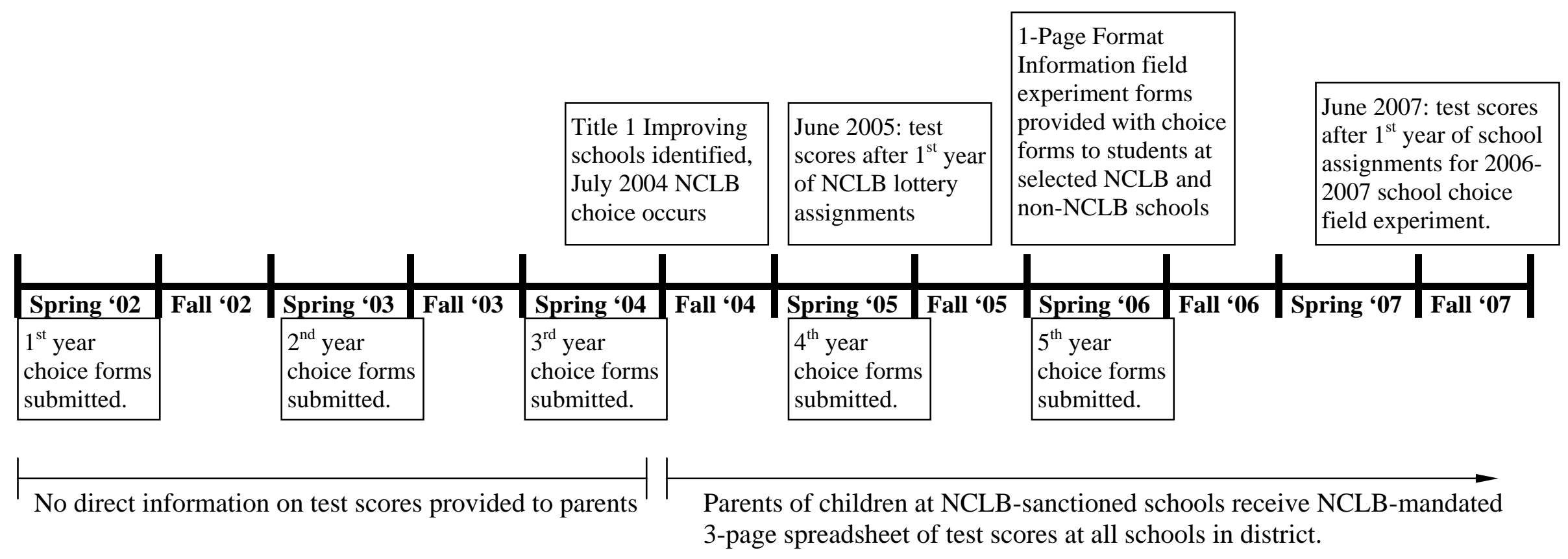

Figure I

Timeline of Events and Information Regimes 


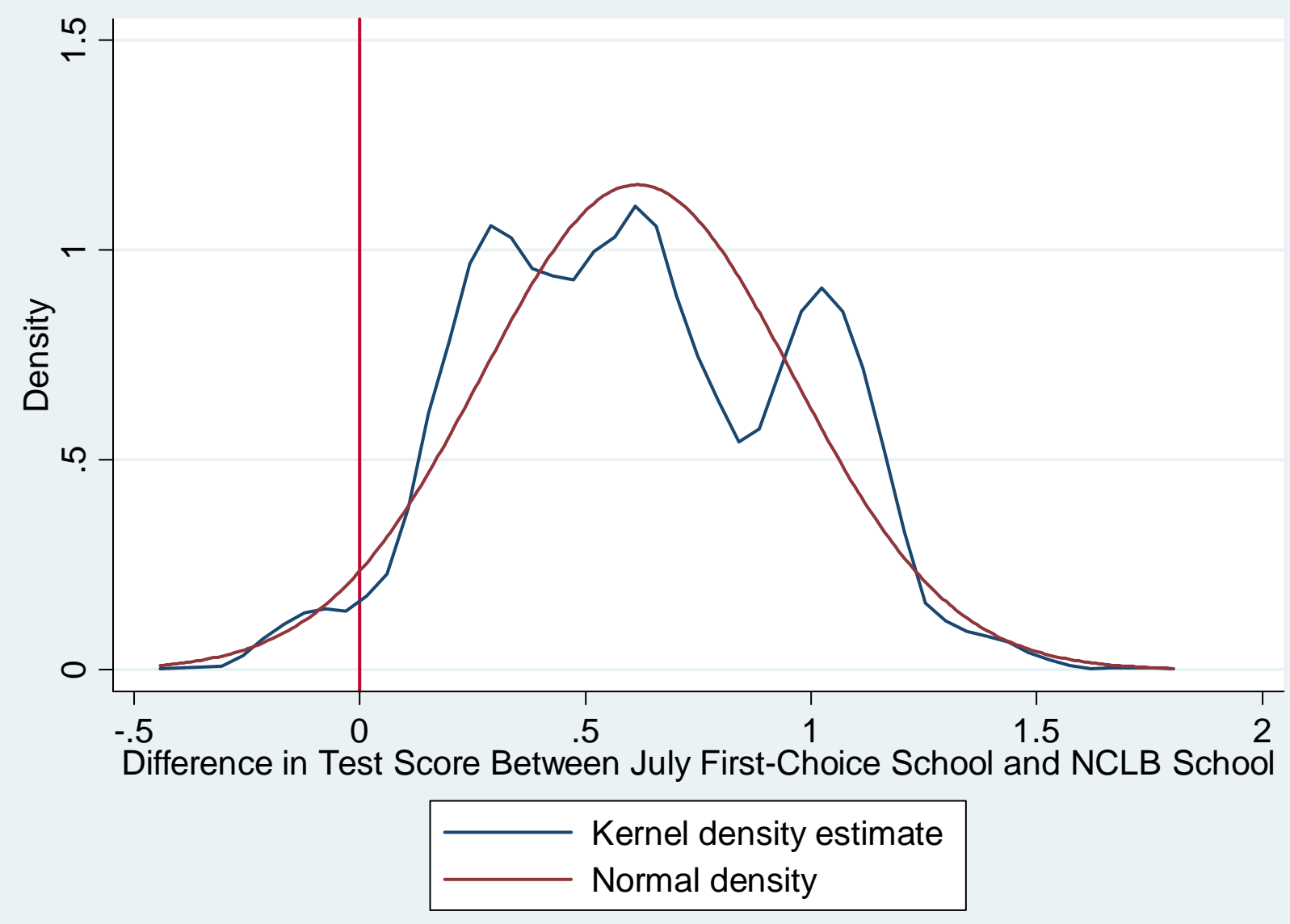

Note: We use the Epanechnikov kernel and the optimal width as computed by default in Stata.

\section{Figure II}

Kernel Density Estimate of Difference in Test Score Between July First-Choice School and NCLB School for Parents Who Chose Out in July, 2004 NCLB Natural Experiment 
vin

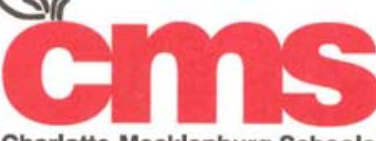

\section{Fast Facts About Your Choice Options}

This table shows student test performance levels at each 2006-

2007 school choice option for your transportation zone.

\begin{tabular}{|c|c|}
\hline Test Score* & School Name and Program \\
\hline $88 \%$ & Villa Heights LI/TD \\
\hline $85 \%$ & Tuckaseegee LI/TD \\
\hline $81 \%$ & Elizabeth Traditional (East Grey Zone) \\
\hline $80 \%$ & Smith Language Academy \\
\hline $80 \%$ & Myers Park Traditional (West Grey Zone) \\
\hline $75 \%$ & Oakhurst Open/Paideia \\
\hline $73 \%$ & Morehead Math/Sci/Env Studies \\
\hline $73 \%$ & First Ward Accelerated Learning \\
\hline $71 \%$ & Highland Mill Montessori \\
\hline $70 \%$ & University Park Arts \\
\hline $69 \%$ & Irwin Ave. Open/Paideia \\
\hline $68 \%$ & Hornets Nest Communication Arts \\
\hline $67 \%$ & Winding Springs Leadership \\
\hline $65 \%$ & Barringer Elementary \\
\hline $65 \%$ & Lincoln Heights Elementary \\
\hline $65 \%$ & Westerly Hills Elementary \\
\hline $63 \%$ & Bruns Elementary \\
\hline $63 \%$ & Druid Hills Elementary \\
\hline $63 \%$ & Walter G. Byers Elementary \\
\hline $63 \%$ & Nathaniel Alexander Elementary \\
\hline $62 \%$ & Ashley Park Elementary \\
\hline $61 \%$ & Reid Park Elementary \\
\hline $60 \%$ & Thomasboro Elementary \\
\hline New School & Irwin Ave. IB \\
\hline New School & Oaklawn Language (K-4) \\
\hline
\end{tabular}

Your Home School is: Druid Hills Elem.

Your Home School Test Score is: $63 \%$

If you would like your child to attend a school other than your home school, you must submit a choice form.

You may submit up to 3 choices, and you are always guaranteed a spot at your home school.

*This score is the average reading and math test score performance on the End of Grade exam for students at this school in the 2004-2005 school year. Information on school-level test score performance can be found for all schools at the CMS web site: www.cms.k12.nc.us.

Prepare for greatness.

Figure III

Example of a Score Form 
Qe

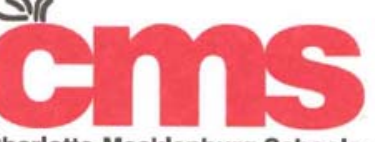

Charlotte-Mecklenburg Schools

\section{Fast Facts About Your Choice Options}

This table shows student test performance levels at each 20062007 school choice option for your transportation zone.

\begin{tabular}{|c|c|c|}
\hline Test Score* & Admit Chance** & School Name and Program \\
\hline $88 \%$ & $62 \%$ & Villa Heights LI/TD \\
\hline $85 \%$ & $95 \%$ & Tuckaseegee LI/TD \\
\hline $81 \%$ & $65 \%$ & Elizabeth Traditional (East Grey Zone) \\
\hline $80 \%$ & $75 \%$ & Smith Language Academy \\
\hline $80 \%$ & $75 \%$ & Myers Park Traditional (West Grey Zone) \\
\hline $75 \%$ & $98 \%$ & Oakhurst Open/Paideia \\
\hline $73 \%$ & $95 \%$ & Morehead Math/Sci/Env Studies \\
\hline $73 \%$ & $45 \%$ & First Ward Accelerated Learning \\
\hline $71 \%$ & $49 \%$ & Highland Mill Montessori \\
\hline $70 \%$ & $92 \%$ & University Park Arts \\
\hline $69 \%$ & $88 \%$ & Irwin Ave. Open/Paideia \\
\hline $68 \%$ & $83 \%$ & Hornets Nest Communication Arts \\
\hline $67 \%$ & $96 \%$ & Winding Springs Leadership \\
\hline $65 \%$ & $68 \%$ & Barringer Elementary \\
\hline $65 \%$ & $98 \%$ & Lincoln Heights Elementary \\
\hline $65 \%$ & $98 \%$ & Westerly Hills Elementary \\
\hline $63 \%$ & $100 \%$ & Bruns Elementary \\
\hline $63 \%$ & $100 \%$ & Druid Hills Elementary \\
\hline $63 \%$ & $100 \%$ & Walter G. Byers Elementary \\
\hline $63 \%$ & $100 \%$ & Nathaniel Alexander Elementary \\
\hline $62 \%$ & $100 \%$ & Ashley Park Elementary \\
\hline $61 \%$ & $100 \%$ & Reid Park Elementary \\
\hline $60 \%$ & $100 \%$ & Thomasboro Elementary \\
\hline New School & New School & Irwin Ave. IB \\
\hline New School & New School & Oaklawn Language (K-4) \\
\hline
\end{tabular}

Your Home School is: Hidden Valley Elem.

Your Home School Test Score is: $\mathbf{6 3} \%$

If you would like your child to attend a school other than your home school, you must submit a choice form.

You may submit up to 3 choices, and you are always guaranteed a spot at your home school.

*This score is the average reading and math test score performance on the End of Grade exam for strdents at this schootin the 20040 2005 school year. Information on school-level test score performance can be found for all schools at the CMS web site: wwiv.cmis.k12. nc.us."* The Admit Chance is the percent of students who listed this choice as their first choice and were admitted through the loftery or off of the wait list for the 2005-2006 school year.

Prepare for greatness.

Figure IV

Example of an Odds Form 


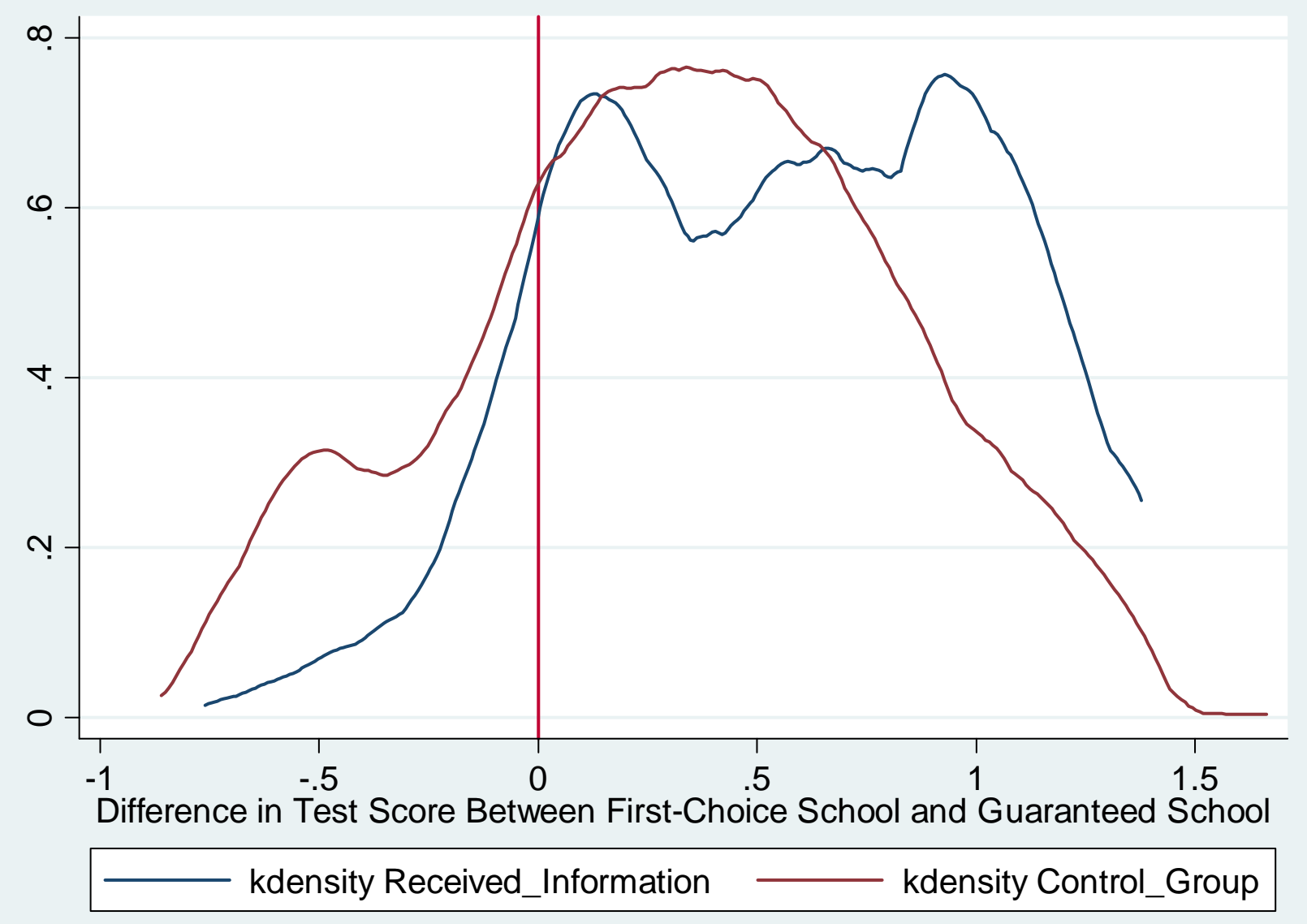

Note: We use the Epanechnikov kernel and the optimal width as computed by default in Stata.

\section{Figure V}

Kernel Density Estimate of Difference in Test Score Between First-Choice School and Guaranteed School for Parents Who Chose Out, 2006 Field Experiment 